$10 / 34.97850$

SAND97-8219 • UC-702

Unlimited Release

497052280

Printed January 1997

\title{
Kinetic Investigation of the Oxidation of Naval Excess Hazardous Materials in Supercritical Water for the Design of a Transpiration-Wall Reactor
}

\author{
S.F. Rice, R.G. Hanush, T.B. Hunter, R.R. Steeper, J.D. Aiken, E. Croiset, \\ C. A. LaJeunesse
}

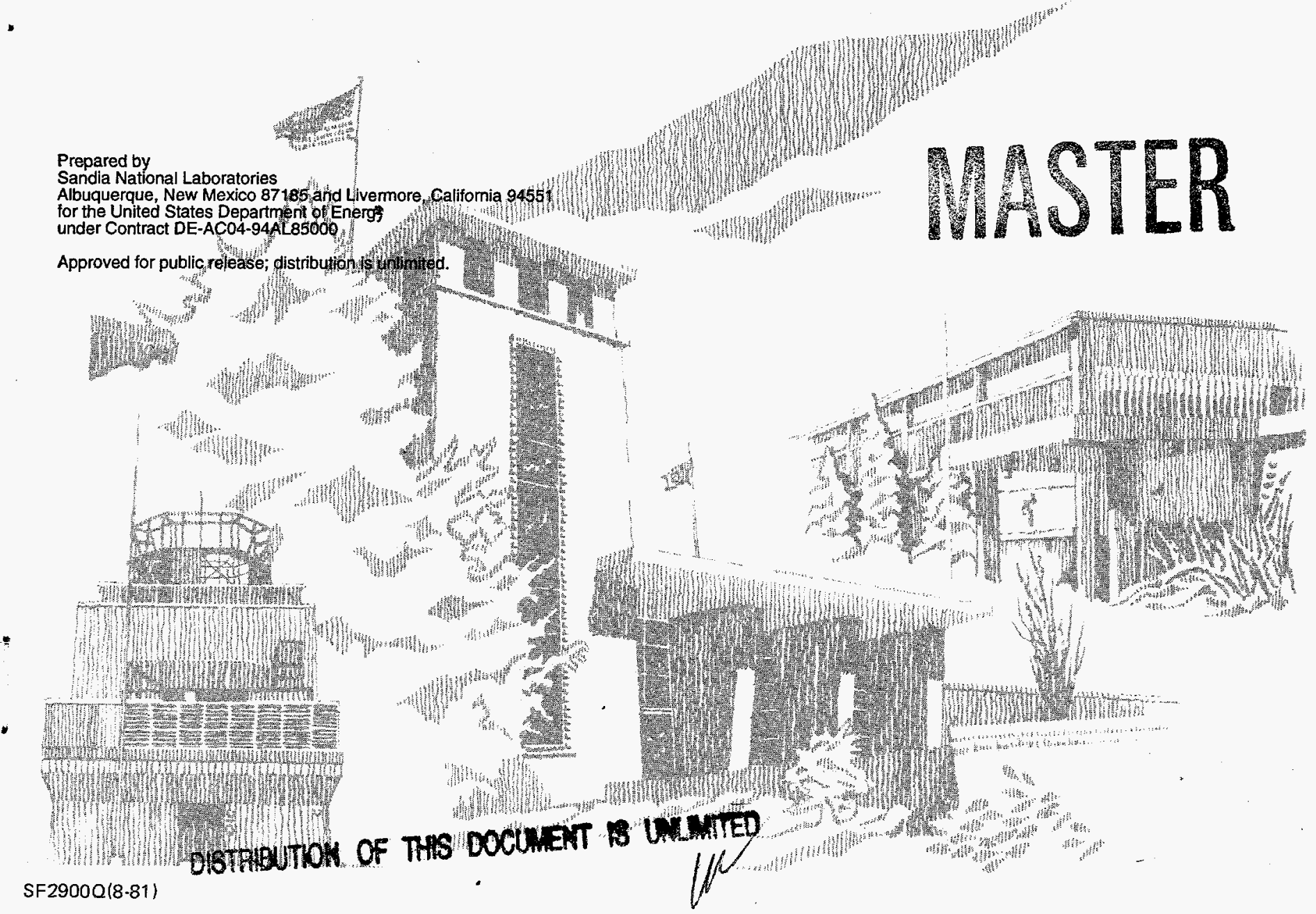


Issued by Sandia National Laboratories, operated for the United States Department of Energy by Sandia Corporation.

NOTICE: This report was prepared as an account of work sponsored by an agency of the United States Government. Neither the United States Government nor any agency thereof, nor any of their employees, nor any of the contractors, subcontractors, or their employees, makes any warranty, express or implied, or assumes any legal liability or responsibility for the accuracy, completeness, or usefulness of any information, apparatus, product, or process disclosed, or represents that its use would not infringe privately owned rights. Reference herein to any specific commercial product, process, or senice by trade name, trademark, manufacturer, or otherwise, does not necessarily constitute or imply its endorsement, recommendation, or favoring by the United States Government, any agency thereof or any of their contractors or subcontractors. The views and opinions expressed herein do not necessarily state or reflect those of the United States Government, any agency thereof, or any of their contractors or subcontractors.

This report has been reproduced from the best available copy.

Available to DOE and DOE contractors from:

Office of Scientific and Technical Information

P.O. Box 62

Oak Ridge TN 37831

Prices available from (615) 576-8401, FTS 626-8401.

Available to the public from:

National Technical Information Service

U.S. Department of Commerce

5285 Port Royal Rd.

Springfield, VA 22161 


\section{DISCLAMMER}

Portions of this document may be illegible in electronic image products. Images are produced from the best available original document. 
UC-702

SAND97-8219

Unlimited Release

Printed January 1997

Kinetic Investigation of the Oxidation of Naval Excess Hazardous Materials in Supercritical Water for the Design of a Transpiration-Wall Reactor

Steven F. Rice, Russell G. Hanush, Thomas B. Hunter, Richard R. Steeper, Jason D. Aiken, Eric Croiset, and Costanzo A. LaJeunesse

Combustion Research Facility

Sandia National Laboratories, Livermore CA

\begin{abstract}
A series of experiments was conducted in Sandia's supercritical fluids reactor (SFR) to generate data for the design of a transpiration-wall supercritical water oxidation (SCWO) reactor. The reactor is intended for the disposal of excess hazardous material generated on naval vessels. The specific design parameters for the system require an accurate knowledge of destruction efficiency vs. time and temperature. Three candidate materials that are present in large quantity on ships were selected for testing. The experiments consisted of oxidizing these materials in Sandia's SFR at isothermal conditions over the temperature range of $400{ }^{\circ} \mathrm{C}-550^{\circ} \mathrm{C}$ at $24.1 \mathrm{MPa}$. A small extrapolation of the results shows that these materials can be adequately destroyed (to $99.9 \%$ destruction removal efficiency, DRE, based on total organic carbon (TOC) in the effluent) in approximately 5 seconds at $600^{\circ} \mathrm{C}$. The results vary smoothly and predictably with temperature such that extrapolation to higher temperatures beyond the experimental capabilities of the SFR can be made with reasonable confidence. The preliminary design of the transpiration-wall reactor has a rapid heat-up section within the reactor vessel that requires the addition of a fuel capable of quickly reacting with oxygen at temperatures below $500{ }^{\circ} \mathrm{C}$. Several candidate alcohols and JP-5 jet fuel were evaluated in this context. The oxidation rates for the alcohols were examined using in situ Raman spectroscopy as the analytical tool. This method permitted the observation of partially oxidized intermediates and a measurement of the formation and consumption of carbon monoxide in the system. In addition, the potential utility of supplying the oxidizer line with hydrogen peroxide as an additive to enhance rapid initiation of the feed at unusually low temperatures was investigated. Experiments were conducted in the Supercritical Constant Volume Reactor (SCVR) using hydrogen peroxide as the initial oxidizing species. The results show that this concept as a method of enhancing low temperature reactivity appears to fail because thermal decomposition of the hydrogen peroxide is more rapid than the fuel oxidation rate at low temperatures.
\end{abstract}





\section{Introduction}

Supercritical water oxidation (SCWO) technology has been demonstrated in the laboratory to be a technically viable waste treatment method for many organic wastes including hazardous wastes generated by routine activities on naval vessels. In 1994, Defense Advanced Research Projects Agency (DARPA) issued BAA \#94-45 to address the on-board remediation of these excess hazardous materials (EHMs). A contract was awarded by DARPA to be administered in conjunction with the Office of Naval Research (ONR) to Foster Wheeler Development Corporation (FWDC). With its partners, GenCorp Aerojet and Sandia National Laboratories, FWDC is developing a SCWO reactor and its supporting systems for this particular application. This team elected to design, fabricate, and test a supercritical water oxidation unit based on a novel reactor design that can effectively solve corrosion and scaling problems that have hindered the widespread application of SCWO. The design of the Transpiration Wall Reactor (TWR) ${ }^{1}$ is based on the principle of containing the reacting material inside a double-walled vessel in which an outer wall provides pressure containment and an inner wall is constructed using transpiration platelet technology. ${ }^{2}$

Sandia's role is to provide engineering design data and laboratory scale development and testing. This activity is divided into two phases. Phase 1 is structured as a series of kinetic measurements on several representative EHMs and potential auxiliary fuels to examine the relative reactivity of these materials as a function of temperature for two purposes: 1 ) determining the reaction time required to achieve a particular destruction efficiency, and 2) evaluate EHMs and other fuels as candidates for the supplemental initiation fuel in the reactor feed injector. This report contains the results and analysis from these tests.

The purpose of the Phase 1 testing at Sandia is not to prove that the TranspirationWall reactor design strategy works. That is the purpose of the Phase 2 and final system testing. The purpose of the Phase 1 experiments is to generate critical design parameters for the full-size reactor with respect to temperature and reaction time operating conditions. Because the reactor is based on transpiration wall technology, many of the issues such as scaling and corrosion associated with an externally heated tubular configuration or autogenic vessel design ${ }^{3}$ are not as important. On the other hand, the key issues associated with the transpiration wall technology are the reaction initiation rate and subsequent heat management requiring a careful selection of operating and physical design parameters. However, an EHM that would be considered challenging to process in a "first generation" SCWO system because of scaling or corrosion, may not be especially difficult in a TWR system.

Most of the experiments described here were conducted in Sandia's Supercritical Fluids Reactor (SFR). This reactor is designed to produce a constant flow rate of supercritical water and reactants at a fixed and constant temperature. The fuel and oxidizer are mixed rapidly at a fixed point and samples can be withdrawn, quenched 
by rapid cooling, and subjected to subsequent analysis. In addition, the composition of the flow can be interrogated spectroscopically through a movable, windowed module.

Destruction efficiency measurements were conducted on three representative EHMs: JP-5 jet fuel; a zinc-containing lubricating oil, Chevron DELO-400; and a hydraulic fluid, Velsicol H-537. All three of these are actual military specification materials. The reactivity of these formulations was measured over a range of reaction temperatures and residence times. Destruction efficiency was characterized by measuring the residual total organic carbon (TOC) in the liquid effluent. These measurements defined the scope of the project.

Experiments conducted on alcohols as candidate reaction initiation fuels used in situ Raman spectroscopy to identify the early-time reactivity of these compounds. This method permits the observation of the formation of intermediate species during the oxidation process and can be used to provide additional information regarding the oxidation mechanism of a particular species. For the purposes of this work, the alcohols were examined spectroscopically to produce a detailed picture of the rate of heat release and formation of carbon monoxide in the reacting system.

An important issue in the TWR design decision process is choosing the feed temperature of the initation fuel and oxidizer stream in the feed injector. Considerable space and energy economy may be found in the feed preheating subsystems if the temperature of these reactants can be lowered below the critical temperature. One promising approach could be to use hydrogen peroxide as part of the oxidizer for the initiation fuel. If $\mathrm{H}_{2} \mathrm{O}_{2}$ is a more reactive oxidizer, presumably by producing a large transient concentration of $\mathrm{OH}$ during its thermal decomposition process, it may serve as a way to generate significant conversion at much lower feed temperature.

The supercritical constant volume reactor (SCVR) was used to examine the effect of hydrogen peroxide on the initiation of a simple reactant, isopropanol, over a reactant temperature range of $340-400{ }^{\circ} \mathrm{C}$ in subcritical and supercritical water. The rate of reaction is compared to the rates observed for the oxidation of isopropanol using $\mathrm{O}_{2}$ as the oxidizer in the SFR.

All of the Phase 1 experiments are designed to answer several important reactor design questions. They are:

1) What is the time/temperature relationship for the destruction of the three representative EHMs to a conversion of $99.9 \%$ and how well can this relationship be extrapolated to temperatures that are not within the operational range of the isothermal supercritical fluids reactor? 
2) What is the time/temperature relationship that produces substantial conversion of the JP-5 and several candidate alcohols to be used as injector reaction initiation fuels?

3) What is the effect of the addition of hydrogen peroxide in the oxidizer feed system and could a method based on $\mathrm{H}_{2} \mathrm{O}_{2}$ in the oxidizer feed be used to lower the required injector initiation temperature?

The answers to these three questions will permit Foster Wheeler and Aerojet to proceed with the reactor designs by specifying: 1) injector flow rates, and therefore pressure drops and orifice sizes, 2) preheat temperatures of all feed fluids including the transpiration water, 3) injector feed fuel and oxidizer compositions, 4) reactor dimensions, and 5) maximum EHM feed rates.

The results from these tests are interpreted in the context of optimizing the design of a the Naval EHM shipboard supercritical water reactor being developed by Foster Wheeler, Aerojet, and Sandia. This is not a complete kinetics investigation of these reacting systems; however, the experimental results are interpreted to permit some generalization regarding the operational design of the shipboard prototype processing unit and to produce some recommendations for injector design strategy and for establishing design setpoints.

\section{Experimental}

\section{Equipment and Operating Methods}

Most of the experiments were conducted using Sandia's Supercritical Fluids Reactor; an isothermal, high-pressure, high-temperature, flow reactor designed to measure reaction kinetics in supercritical fluids over a wide range of feed concentrations, pressures, and temperatures. The Supercritical Constant Volume Reactor was used for lower-temperature, i-propanol/hydrogen peroxide reaction initiation measurements.

\section{Supercritical Fluids Reactor}

The Supercritical Fluids Reactor, pictured in Figure 1, is designed to examine technical issues associated with the development of the SCWO process. A report containing a detailed description of the SFR and the procedures associated with collection and analysis of results from a variety of experimental techniques is available elsewhere. 4 In that report, the equipment used for experimental operations is presented in detail along with a description of the control and data acquisition hardware. Procedures for operation and data acquisition are detailed in sections on maintenance, optical alignment, setup of the apparatus and peripheral 


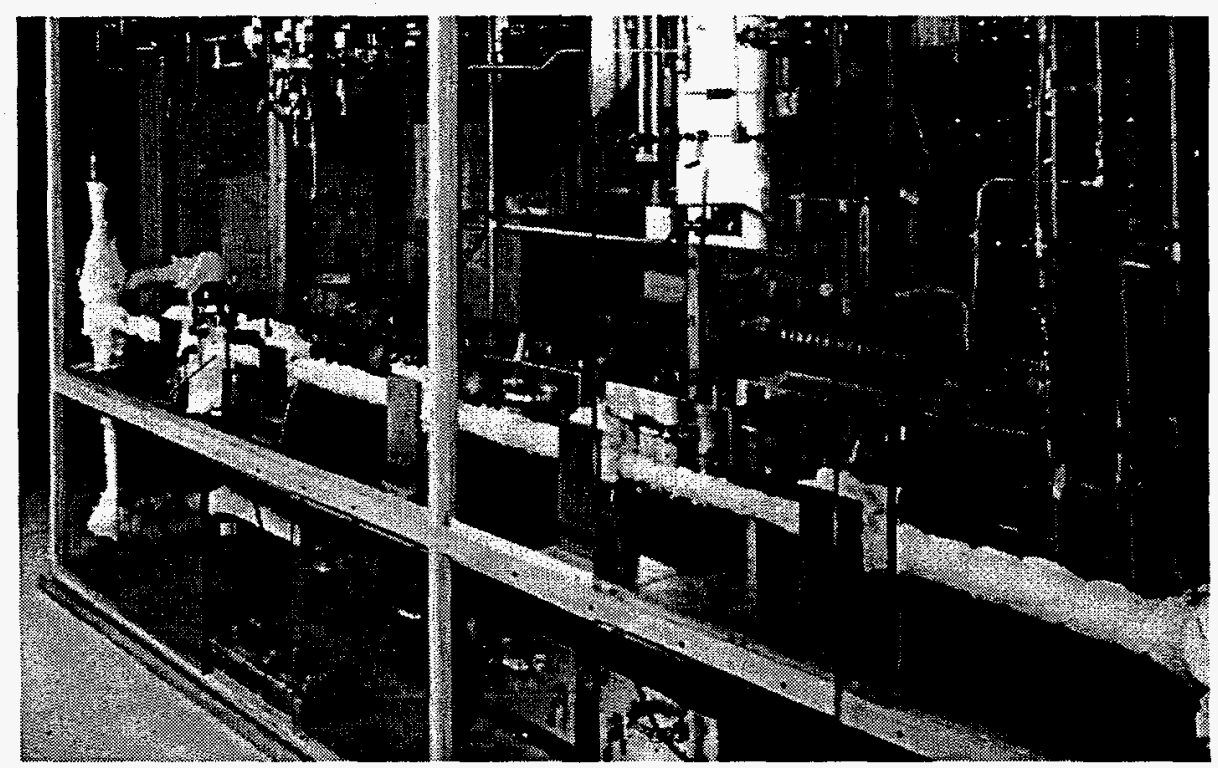

Figure 1. Photograph of the Supercritical Fluids Reactor used for most of the testing presented in this report.

hardware, reactor start-up, experimental procedures, and shutdown of the apparatus. The following is a brief discussion of the procedures used for these specific tests on EHMs.

The SFR, shown schematically in Figure 2, consists of 7 operational subsystems (pressurization, feed, two parallel preheat subsystems, reactor, cool down, and separation). Control and data acquisition hardware and software are also an integral part of the entire reactor system. These subsystems provide an overall reactor that is capable of a wide range of experimental parameters and configurations.

Flow of the reactants begins in the feed subsystem where supplies to the highpressure pumps are generated. The low pressure feeds flow to the two parallel preheat subsystems for pressurization and heating. After pressurization, the flows can be diverted to a single preheat line and mixed prior to heating, or preheated separately and mixed at experimental conditions. Flow continues through the reactor subsystem, which is kept at isothermal conditions during the reaction. This section allows optical accessibility to the reacting flow. Upon exiting the reactor subsystem, the flow is cooled to ambient temperature in the cool-down subsystem. The separation subsystem removes any solids produced during the process from the liquid and gaseous components of the flow stream. After separation, each component may be collected for analysis and later disposal. 


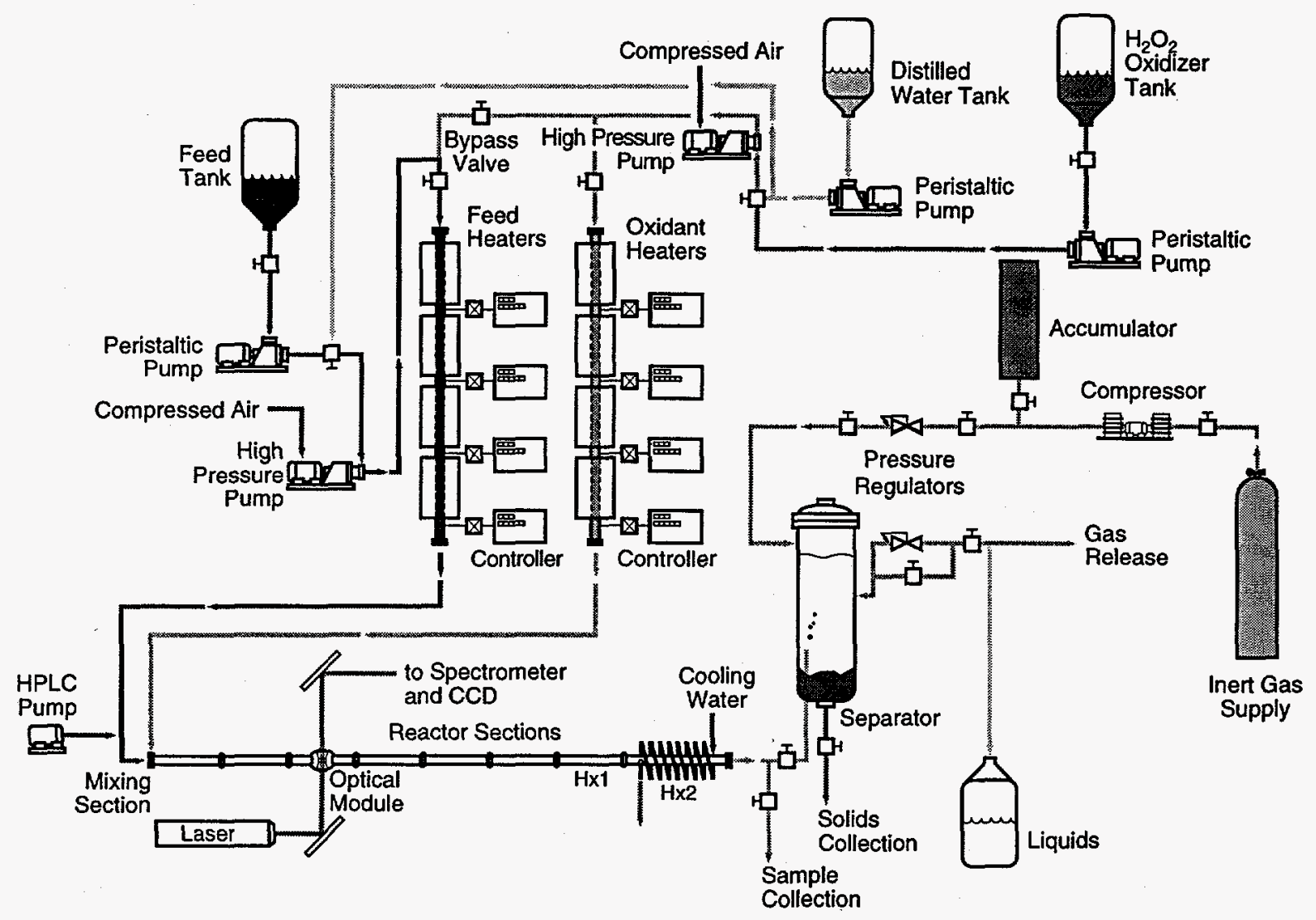

Figure 2. Schematic diagram of the Supercritical Fluids Reactor.

Depending on specific conditions, a small fraction of reactant can pyrolyze in the several seconds it spends in the preheat zone, so the system is designed such that reactants can either be mixed in the feed line prior to the pressurization system or added immediately prior to mixing with the oxidizer. A high-pressure liquid chromatography pump (HPLC) is used to provide this second injection option. Typically, the feed is injected into a supercritical water flow that is over 100 times greater than the reactants. Therefore, cold reactant does not noticeably change the temperature of the feed flow, and the possibility of pyrolysis or hydrolysis reactions modifying the nature of the feed prior to oxidation is removed. In a real application, it is not likely that an injection strategy such as this would be necessary, but we have found that this is needed to obtain accurate oxidation kinetics of a welldefined chemical species. With this method, which is used in all of the experiments reported here, the time at high temperature the feed reactant experiences without the presence of an oxidizer is in the range of 0.1-0.3 s.

All of the experiments conducted in the SFR involved the same basic operational method. Isothermal conditions were established using a water feed in the feed line and a solution of hydrogen peroxide in the oxidizer line. The organic liquid being studied was injected as a pure fluid through the HPLC pump at a measured rate 
producing a predetermined mole fraction in the feed. The injection point was located approximately $15 \mathrm{~cm}$ prior to the mixing point with the oxidizer. During the course of preheating, the hydrogen peroxide in the oxidizer line thermally disproportionates to form water and oxygen. The residence time in the oxidizer preheater was sufficient to completely convert all of the hydrogen peroxide to oxygen. ${ }^{5}$ Thus the reaction kinetics that are measured result from the reaction of the feed organic with oxygen, not hydrogen peroxide. Reaction times are calculated based on a plug flow model that relates position along the length of the reactor to time. The Reynolds number for the flow ranged from 5600 to 12000 depending on operating conditions; the flow is turbulent, assuring that plug flow conditions are met.

By varying the flow rates and the sampling position a range of reaction times could be accessed. All experiments were conducted at $24.5 \mathrm{MPa}(3550 \mathrm{psi})$. The fuel feed concentration for the EHM experiments was chosen to be $0.5 \mathrm{wt} \%$. The concentration for the propanol experiments was $1.0 \mathrm{wt} \%$.

Samples for analysis were obtained through a high-pressure capillary sample tube (not shown in Fig. 2) that can be positioned anywhere along the length of the reactor. These samples are typically only a very small fraction of the total flow. The sample is quenched in less that $10^{-2} \mathrm{~s}$ by immersing the sample tube in a cold water bath. For the tests conducted here on the EHMs, this "short-reaction-time (S)" sample position was located $61 \mathrm{~cm}$ from the mixing point. Alternatively, samples can be taken of the entire effluent by diverting the flow through the sample collection and pressure let-down port immediately following the main heat exchanger. In these experiments, this position (designated "long-reaction-time (L)" ) is $380 \mathrm{~cm}$ from the mixing point.

\section{Supercritical Constant Volume Reactor}

Experiments on the application of low-temperature injection of hydrogen peroxide as an oxidizer were conducted in the supercritical constant volume reactor (SCVR). A cross-sectional view of this reactor is presented in Figure 3. The reactor is constructed from a single piece of Inconel 718 and has five fluid access ports and three sapphire optical windows. The operation of this reactor and its ancillary equipment are described elsewhere. ${ }^{6}$

For these experiments, the $\mathrm{H}_{2} \mathrm{O}_{2}$ was rapidly injected through high-pressure capillary tubing by a hand-operated, high-pressure piston into a preheated mixture of i-propanol in sub- or supercritical water. The concentration of the i-propanol was monitored continuously using Raman spectroscopy. Spectra were recorded at $10 \mathrm{~s}$ intervals and integrated to obtain the fraction of the initial i-propanol concentration present in the reactor as a function of time. 


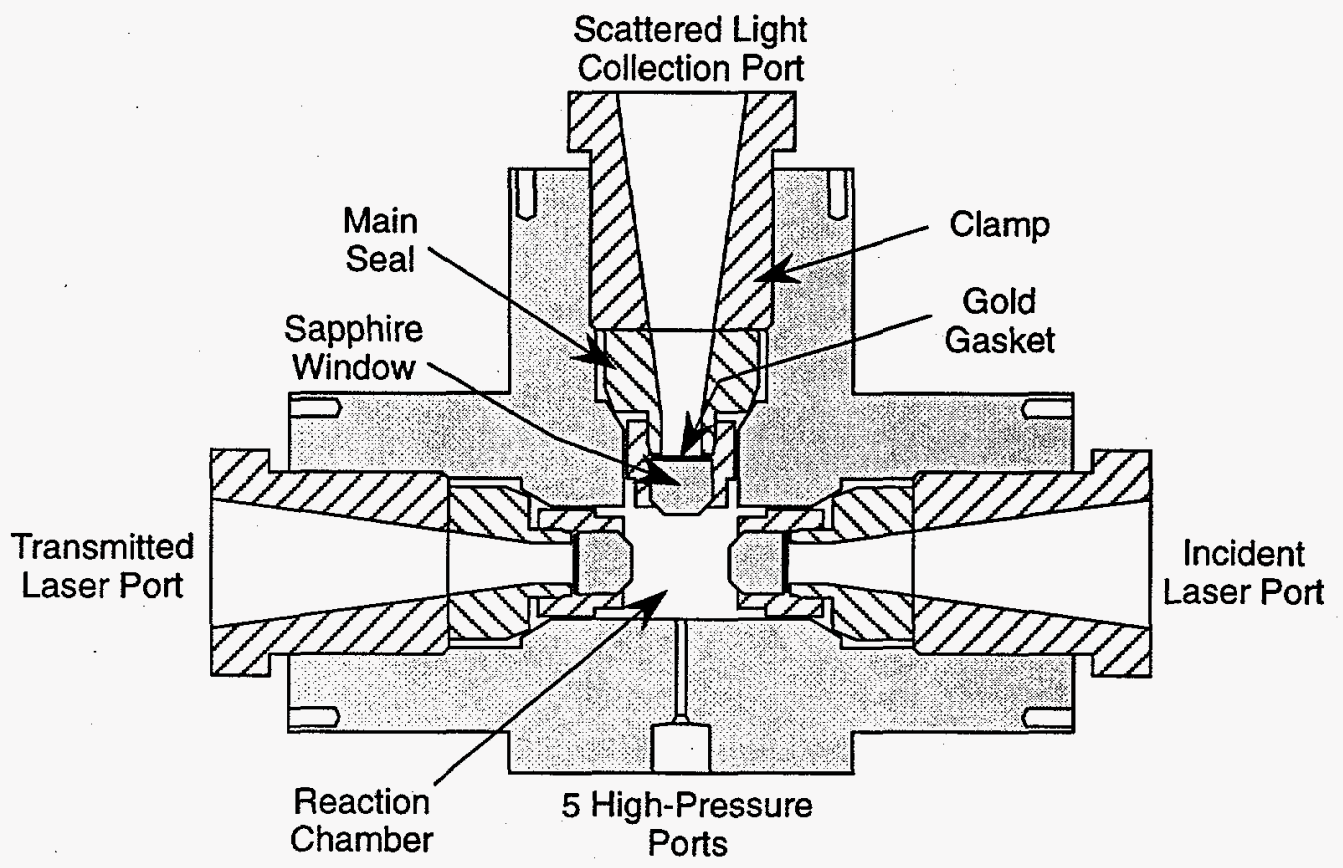

Figure 3. Cutaway view of the optically accessible supercritical constant volume reactor (SCVR). The reactor volume is approximately $22 \mathrm{~cm}^{3}$ with optical access provided on three sides.

\section{Analytical Methods}

Total Organic Carbon (TOC) was used as the analytical method for determining destruction of the EHM feeds. In situ Raman spectroscopy was used to determine the initiation reactivity of the alcohols. The Raman method provides much more detailed information about the heat release as a function of time, but is not easily applied to mixtures such as the EHM's which are not single-species materials.

The TOC measurements were conducted using a Rosemount Model LD190 TOC analyzer. This analytical instrument works on the principle of oxidizing an aliquot of the sample at high temperature and then measuring the evolved $\mathrm{CO}_{2}$ using infrared spectrometry after correcting for any dissolved $\mathrm{CO}_{2}$ initially in the sample. When calibrated, it is capable of measuring the organic carbon dissolved in water over a range of $1-2000 \mathrm{ppm}$ with an accuracy of $\pm 1 \%$. Since only liquid samples were collected during these tests, this method does not distinguish between feed carbon that has been fully converted to $\mathrm{CO}_{2}$ and material that has been to oxidized to $\mathrm{CO}$. These gaseous effluents leave the reactor as vapors, except for the small fraction of $\mathrm{CO}_{2}$ that is soluble in the liquid sample at ambient pressure.

The reaction initiation measurements on i-propanol and n-propanol reported here used Raman spectroscopy to provide a more accurate picture of the formation of $\mathrm{CO}$ and $\mathrm{CO}_{2}$ and to allow for a more accurate evaluation of the rate of heat release from 
the reacting system. These data include not only the measurement of the loss of the initial fuel species, but also the production and subsequent consumption of key intermediates.

The optical spectroscopic measurements can be made at any number of positions along the reactor. Again, by varying flow rate and sample position, and converting reactor length to an effective reaction time, a wide range of times can be sampled. To generate the Raman scattering signal, the probe volume is excited with an argon ion laser. The power of the Raman signal, $P_{r}$, can be expressed as

$$
\mathrm{P}_{\mathrm{r}}=\mathrm{P}_{\mathrm{i}} \mathrm{n}\left(\frac{\partial \sigma}{\partial \Omega}\right) \Omega \ell \varepsilon
$$

where $P_{i}$ is the pump laser power, $n$ is the species number density, $\partial \sigma / \partial \Omega$ is the differential Raman cross section, $\Omega$ is the collection solid angle, $\ell$ is the sampling pathlength, and $\varepsilon$ is the collection efficiency. It is evident that the Raman signal power is directly proportional to the species number density. Therefore, by integrating the intensity of an observed Raman transition, a value which is proportional to the species concentration can be obtained. In addition, it has been shown that the Raman signal intensity is independent of the surrounding species concentrations at these water densities, $, 6,7$ allowing the absolute concentration of a species to be calculated following calibration of the system.

\section{Materials}

All three EHMs are various compositions of hydrocarbons with selected additives. None of these feeds contained a significant fraction of heteroatoms such as nitrogen, sulfur, or chlorine.

$J P-5$

Jet Fuel Grade JP-5 was obtained in a 55 gal drum from Alameda Naval Air Station. The MSDS was supplied by Exxon Company USA. Its components are hydrotreated light petroleum distillates (approx. 100\%) with an average molecular weight of 185 . It is essentially kerosene. Anti-oxidants and a metal deactivator are present at less that $100 \mathrm{ppm}$ as additives. It has a specific gravity range of $0.788-0.845$ and has negligible solubility in water $(<0.1 \%)$. Toxic fumes may be produced from incomplete combustion. NSN 9140-002732379.

DELO-400 lubricating oil

DELO-400 lubricating oil and the MSDS were obtained from Chevron Corp. It is described as a base oil containing severely refined petroleum distillate $(80 \%)$ with $<1.6 \%$ zinc alkyl dithiophosphate as an additive. It has a specific gravity of 0.88 and is insoluble in water. Toxic fumes may be produced from incomplete combustion. NSN 9150-001866681, MIL-L-2104E. 
Velsicol H537 hydraulic fluid

H537 synthetic hydrocarbon hydraulic fluid and the MSDS were obtained from Velsicol Corp. It is a red clear liquid and is insoluble in water. Its composition is not well characterized in the data available. Burning will produce toxic fumes. NSN $9150-001497432$, MIL-H-83282C.

\section{Results and Discussion}

\section{Destruction Efficiency of EHMs - First Order Analysis}

Tables 1-3 show the results from the measurements of the destruction efficiency of the three representative EHMs: JP-5 jet fuel, Chevron Delo 400 lubricating oil, and Velsicol H537 hydraulic fluid. The tables list the measured output TOC for a given residence time and temperature. The jet fuel was examined much more thoroughly than the other materials because of the interest in using it as an initiation fuel. The flow parameter identifies the high-pressure pump frequency in piston strokes per minute and the sample position/reaction time as short (S) or long (L).

There are several different ways to view these data, depending on whether the emphasis of the analysis is on high conversion at high temperature, for destruction efficiency design, or on low conversion at low temperature, for initiation and highenergy-release considerations. The interest in JP- 5 originates not only from its being one of the largest volume EHMs, but also from its potential use as an initiation fuel. We will address JP-5 conversion efficiency first. An investigation of short time reactivity will follow.

For all three EHMs, the feed TOC could not be measured because these materials are extremely insoluble in water and the precise molecular composition of these materials is not known. As a result, the fraction of the TOC converted, $C / C_{0}$, is based on an estimated feed TOC. The three materials were estimated as being simple hydrocarbons of composition $(-\mathrm{CH} 2-)_{\mathrm{n}}$. This is a good approximation for the jet fuel, since it is essentially kerosene, primarily composed of aliphatic hydrocarbons. The lubricating oil is also primarily composed of aliphatic hydrocarbons. The composition of the hydraulic fluid is not known; it is most likely a mixture of synthetic hydrocarbons.

Figure 4 shows the results from the JP- 5 tests. The distribution of $C / C_{o}$ at a given temperature shows the range of conversion for different reaction times. The line on the plot shows conversion as a function of time temperature for a residence time of $5.5 \mathrm{~s}$. Special emphasis is placed on this reaction time since it is a preliminary design parameter in the TWR. It indicates that $99.9 \%$ of the organic carbon is converted to $\mathrm{CO}_{2}$ or $\mathrm{CO}$ at $565{ }^{\circ} \mathrm{C}$. The figure emphasizes the importance of temperature in this system: a small change in the operating temperature of the reactor will produce a 
Table 1 - JP-5 Oxidation Results

\begin{tabular}{|c|c|c|c|}
\hline $\mathrm{T}\left({ }^{\circ} \mathrm{C}\right)$ & $\begin{array}{c}\text { Flow } \\
\text { Parameters }\end{array}$ & $\begin{array}{l}\text { Reaction } \\
\text { time (s) }\end{array}$ & $\begin{array}{l}\text { TOCa } \\
\text { (ppm) }\end{array}$ \\
\hline 388 & $24 \mathrm{~S}$ & 2.91 & 1708 \\
\hline 390 & $24 \mathrm{~L}$ & 18.1 & 1001 \\
\hline 393 & 365 & 1.93 & 1780 \\
\hline 393 & $36 \mathrm{~L}$ & 12.0 & 1098 \\
\hline 392 & $55 \mathrm{~S}$ & 1.26 & 1921 \\
\hline 392 & $55 \mathrm{~L}$ & 7.88 & 1330 \\
\hline 420 & $24 S$ & 1.96 & 1198 \\
\hline 420 & $24 \mathrm{~L}$ & 12.2 & 674 \\
\hline 422 & $36 \mathrm{~S}$ & 1.30 & 1675 \\
\hline 421 & $36 \mathrm{~L}$ & 8.09 & 820 \\
\hline 424 & $55 S$ & 0.85 & 1095 \\
\hline 424 & $55 \mathrm{~L}$ & 5.30 & 1929 \\
\hline 459 & $24 S$ & 1.57 & 622 \\
\hline 463 & $24 \mathrm{~L}$ & 9.82 & 227 \\
\hline 460 & $36 \mathrm{~S}$ & 1.04 & 864 \\
\hline 462 & $36 \mathrm{~L}$ & 6.51 & 340 \\
\hline 465 & $55 S$ & 0.68 & 1175 \\
\hline 465 & $55 \mathrm{~L}$ & 4.26 & 408 \\
\hline 500 & $24 S$ & 1.35 & 222 \\
\hline 501 & $24 \mathrm{~L}$ & 8.43 & 40.4 \\
\hline 501 & $36 \mathrm{~S}$ & 0.90 & 287. \\
\hline 503 & $36 \mathrm{~L}$ & 5.59 & 84 \\
\hline 500 & $55 S$ & 0.59 & 394 \\
\hline 499 & $55 \mathrm{~L}$ & 3.66 & $23.1^{b}$ \\
\hline 518 & $24 S$ & 1.29 & 142 \\
\hline 519 & $24 \mathrm{~L}$ & 8.03 & 4.95 \\
\hline 520 & 365 & 0.86 & 163 \\
\hline 522 & $36 \mathrm{~L}$ & 5.32 & 11.48 \\
\hline 520 & $55 \mathrm{~S}$ & 0.56 & 190 \\
\hline 520 & $55 \mathrm{~L}$ & 3.49 & 67.7 \\
\hline 540 & $24 S$ & 1.20 & 57.2 \\
\hline 549 & $24 \mathrm{~L}$ & 7.47 & 6.43 \\
\hline 551 & 365 & 0.79 & 83.3 \\
\hline 555 & $36 \mathrm{~L}$ & 4.96 & 8.23 \\
\hline 558 & $55 \mathrm{~S}$ & 0.52 & 120.0 \\
\hline 556 & $55 \mathrm{~L}$ & 3.24 & 13.3 \\
\hline
\end{tabular}

${ }^{a}$ feed TOC $=4225 \mathrm{ppm},{ }^{b}$ poor temperature control 
Table 2 - Delo 400 Lubricating Oil

\begin{tabular}{|c|c|c|c|}
\hline $\mathrm{T}\left({ }^{\circ} \mathrm{C}\right)$ & $\begin{array}{c}\text { Flow } \\
\text { Parameters }\end{array}$ & $\begin{array}{l}\text { Reaction } \\
\text { time (s) }\end{array}$ & $\begin{array}{l}\text { TOC } \\
\text { (ppm) }\end{array}$ \\
\hline 400 & $36 \mathrm{~S}$ & 1.59 & 227 \\
\hline 400 & $36 \mathrm{~L}$ & 9.93 & 101.9 \\
\hline 449 & $36 \mathrm{~S}$ & 1.08 & 43.3 \\
\hline 450 & $36 \mathrm{~L}$ & 6.77 & 38.1 \\
\hline 500 & $36 \mathrm{~S}$ & 0.90 & 4.57 \\
\hline 500 & $36 \mathrm{~L}$ & $\overline{5.59}$ & 30.1 \\
\hline 550 & $36 \mathrm{~s}$ & 0.79 & 1.56 \\
\hline 550 & $36 \mathrm{~L}$ & 4.96 & 16.3 \\
\hline 550 & $55 \mathrm{~S}$ & 0.52 & 0.87 \\
\hline 550 & $55 \mathrm{~L}$ & 3.24 & 8.43 \\
\hline 550 & $24 \mathrm{~S}$ & 1.20 & 0.83 \\
\hline 550 & $24 \mathrm{~L}$ & 7.47 & 1.61 \\
\hline
\end{tabular}

Table 3 - Velsicol H537 Hydraulic Fluid

\begin{tabular}{|c|c|c|c|}
\hline $\mathrm{T}\left({ }^{\circ} \mathrm{C}\right)$ & $\begin{array}{c}\text { Flow } \\
\text { Parameters }\end{array}$ & $\begin{array}{l}\text { Reaction } \\
\text { time (s) }\end{array}$ & $\begin{array}{l}\text { TOC } \\
\text { (ppm) }\end{array}$ \\
\hline 405 & $36 \mathrm{~S}$ & 1.50 & 1120 \\
\hline 405 & $36 \mathrm{~L}$ & 9.34 & 820.2 \\
\hline 420 & $36 \mathrm{~S}$ & 1.30 & 1021 \\
\hline 420 & $36 \mathrm{~L}$ & 8.09 & 564 \\
\hline 450 & $36 \mathrm{~S}$ & 1.08 & 642 \\
\hline 450 & $36 \mathrm{~L}$ & 6.77 & 254 \\
\hline 500 & $36 \mathrm{~S}$ & 0.90 & 109 \\
\hline 500 & $36 \mathrm{~L}$ & 5.59 & 27.2 \\
\hline 550 & $36 \mathrm{~S}$ & 0.79 & 42.2 \\
\hline 550 & $36 \mathrm{~L}$ & 4.96 & 10.0 \\
\hline
\end{tabular}




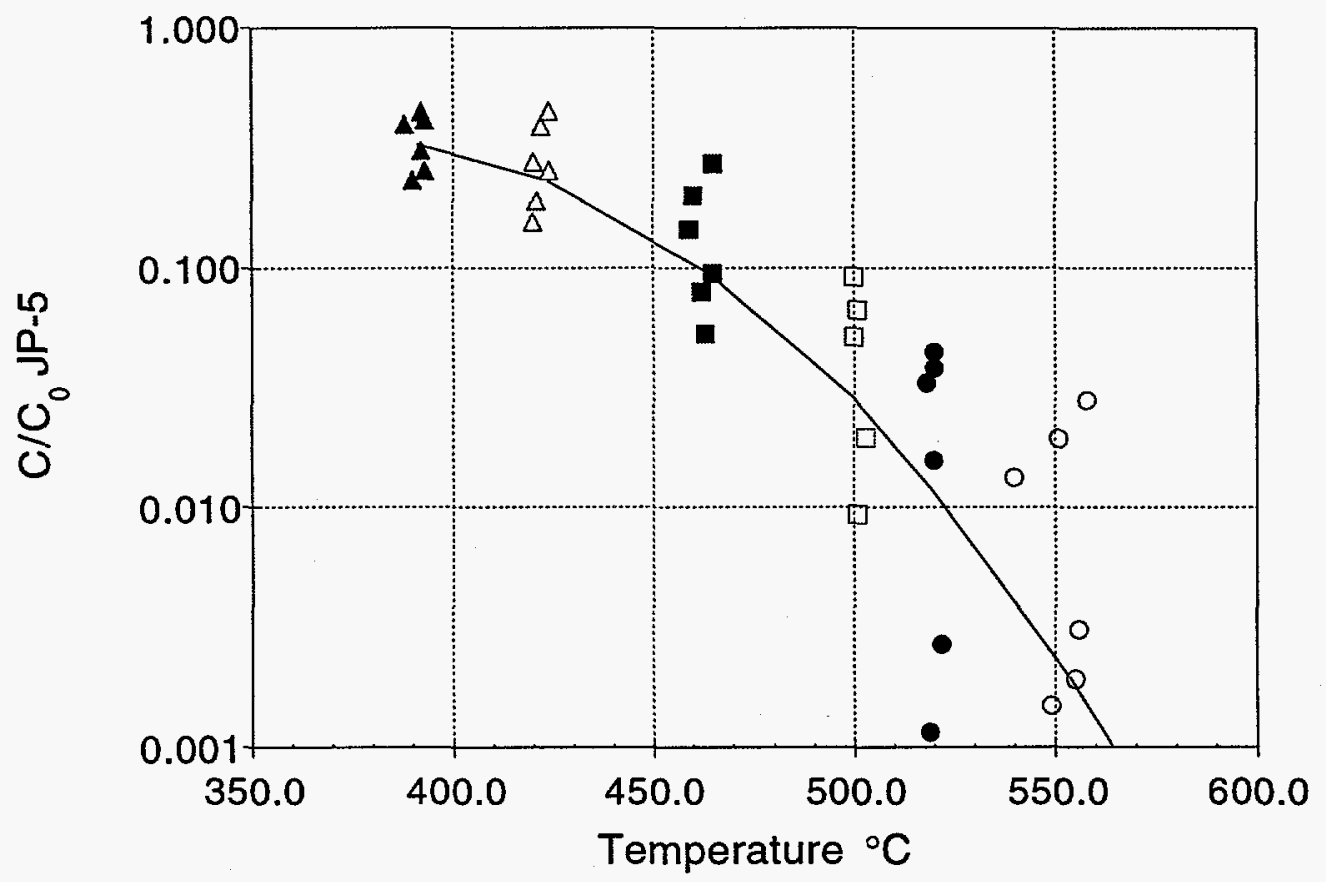

Figure 4. TOC in the liquid effluent $(C)$ normalized by the calculated feed TOC (see text, $\mathrm{C}_{\mathrm{o}}=4225 \mathrm{ppm}$ ) from the oxidation of JP-5 by oxygen in supercritical water at various reaction temperatures. The spread in the data reflects the different reaction times. The line indicates the interpolated $\mathrm{C} / \mathrm{C}_{\mathrm{o}}$ for a reaction time of $5.5 \mathrm{~s}$.

very large change in the conversion efficiency (note the logarithmic ordinate) for a given residence time.

Figure 5 shows these results plotted in a conversion $\left(C / C_{0}\right)$ vs. time format. This plot shows unexpected behavior at times less than one second. Not only is there no induction time apparent for the reaction of this material, but there is, in fact, a very rapid reaction that consumes a significant amount of the fuel at very early times. This behavior points to the potential use of this material as an initiation fuel in the TWR, establishing that there is no delay in heat release after mixing fuel and oxidizer.

It is possible to express these results as an effective conversion rate, $k_{e f f}$, which is a pseudo-first-order rate constant defined as

$$
k_{\text {eff }}=-\ln \left(C / C_{o}\right) / t
$$




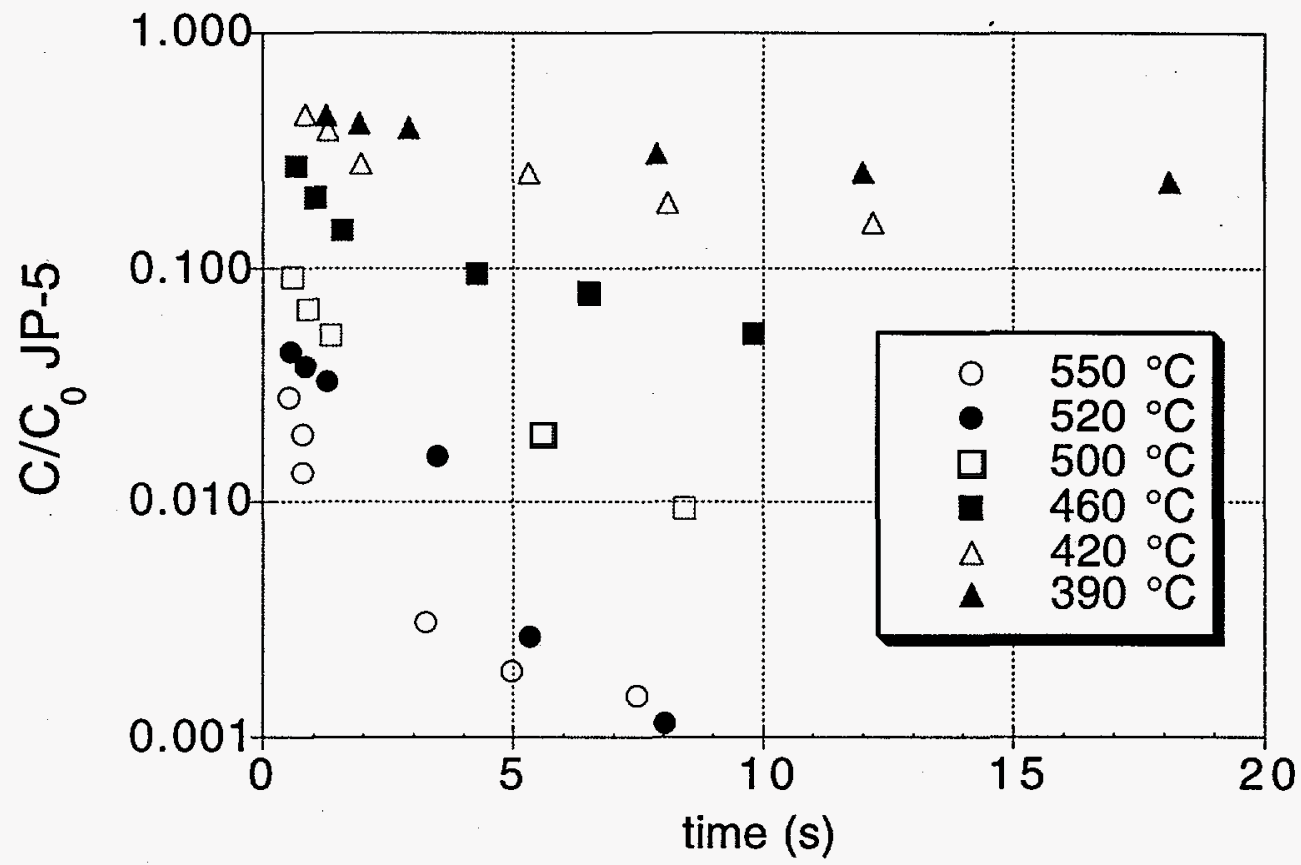

Figure 5. TOC in the liquid effluent (C) normalized by the calculated feed TOC (see text, $\mathrm{C}_{\mathrm{o}}=4225 \mathrm{ppm}$ ) from the oxidation of JP-5 by oxygen in supercritical water at various reaction temperatures as a function of time.

derived from integrating

$$
\mathrm{dC} / \mathrm{dt}=-\mathrm{k}_{\mathrm{eff}} \mathrm{C}
$$

with $\mathrm{C}_{\mathrm{o}}$ being the initial fuel TOC concentration. Figure 6 displays this rate constant plotted in Arrhenius format, where the effective rate constant, $k_{\text {eff }}=A \exp \left(-E_{a} / R T\right)$. Note that approximately parallel straight lines are obtained for the different reaction times permitting the data to be reduced to an activation energy and a set of preexponential factors that depend on the reaction time. That is, at each temperature there is a series of effective rate constants with the largest values corresponding to the shortest reaction times. In a true first order system, all the data points for a given temperature would be identical. This is not the case for these data. To understand this physically, we need to examine the assumptions made expressing these data as an effective first-order rate. 


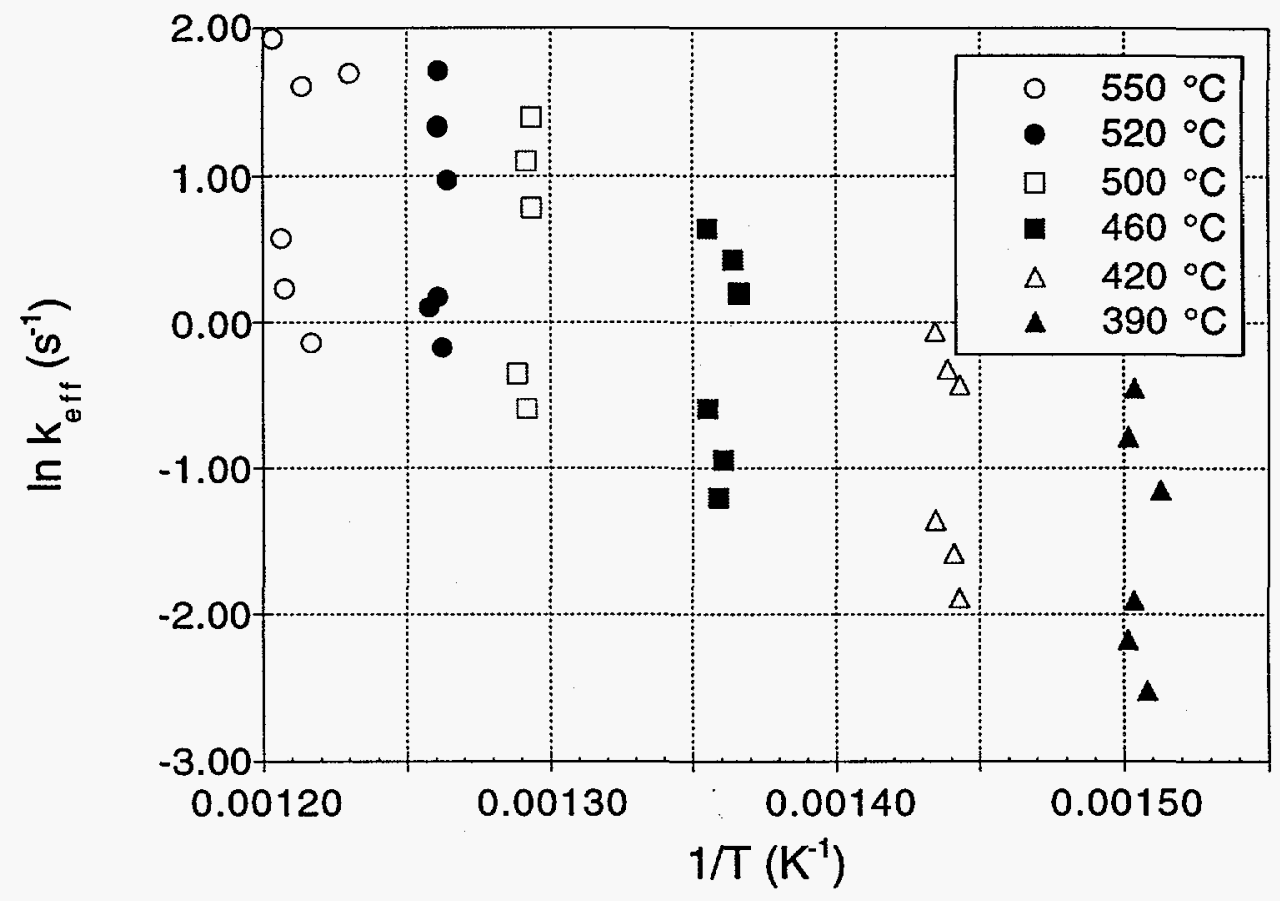

Figure 6. Effective first order rate constant derived from Eq. 2 and the JP-5 data in Table 1 expressed in Arrhenius format.

The oxidation of a fuel in supercritical water is essentially a radical-chain system such that the actual oxidizing molecular species, from an elementary reaction standpoint, are probably $\mathrm{OH}$ and $\mathrm{HO}_{2}$, not $\mathrm{O}_{2}$. As a result, hidden in the first-order expression (and ultimately in the preexponential factor) is the time dependence of the concentration of these key reactive species. At high fuel concentrations, these radicals are much more rapidly produced through chain-branching reactions that depend on fuel concentration. The high radical concentration results in high apparent rate constants. After a brief time, the fuel concentration is reduced and the reaction rate falls off, resulting in an net decreased fuel-consumption rate constant for longer reaction times and greater conversion.

From an engineering-design standpoint, the consistent slope of $\mathrm{k}_{\mathrm{eff}}$ over a range of temperatures provides confidence in predicting the reaction rate constant at temperatures higher than could be obtained in the SFR as it is presently configured (e.g. $600-700^{\circ} \mathrm{C}$ ).

Figure 7 compares the measured rate constants for the oxidation of the three EHMs in Arrhenius format taken from the 36L samples; corresponding to reaction times 
ranging from 5-9 seconds. It appears that the behavior of the hydraulic fluid and the jet fuel are similar. This is to be expected since the two materials are primarily light hydrocarbon chains. The oil, having a smaller activation energy, appears to be a little more reactive. This may be due to the composition or it could possible be due to some catalytic activity from the zinc that is present in the feed (or possibly from zinc oxide that is rapidly formed, see Materials in the Experimental Section). Catalytic activity in the oxidation of organics in supercritical water has been reported for a variety of metal oxides. At higher temperatures, where the homogenous oxidation rate would be less affected by catalysis, the destruction rate for all three materials is essentially the same.

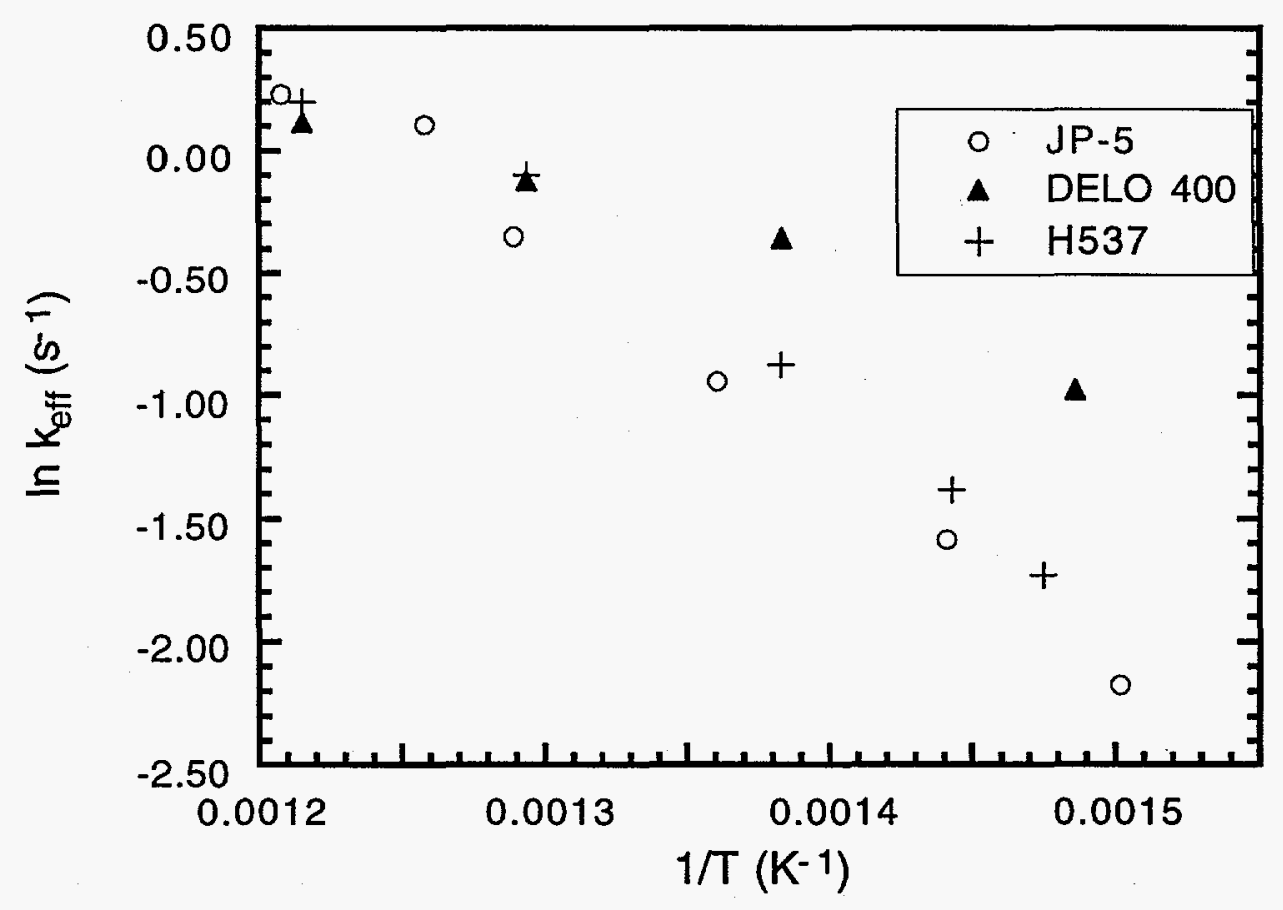

Figure 7. Arrhenius plot of the effective first-order rate constant for the oxidation of the three EHMs in supercritical water evaluated at the $36 \mathrm{~L}$ flowrate and sample position.

\section{Data Set Interpretation and Sequential Reaction Analysis}

There are two separate, but related, aspects of the sample collection method and the analytical method (TOC) that require some additional discussion. The first issue is the apparently physically unreasonable observation in the lubricating oil data set showing less TOC observed for short residence times (the "short-residence-time" sample position) than for long ones at the same temperature (above $500{ }^{\circ} \mathrm{C}$ ). The 
other issue concerns the nature of TOC analysis of dilute mixtures containing insoluble components. These remaining issues are the result of the limited scope of this research activity, which was specifically designed to characterize destruction efficiency only in terms of liquid effluent composition and not to consider the composition of the effluent gases.

\section{Lubricating oil}

The data in Table 2 at $500{ }^{\circ} \mathrm{C}$ and $550{ }^{\circ} \mathrm{C}$ show what appears to be a physically impossible result. The TOC measured for short residence times (samples from the capillary tube) is actually less than that recorded for the longer residence time (sampled from the total effluent of the reactor). There are two possible explanations for this. The first is that the oil takes a long time to mix with the supercritical water after it is injected into the preheated flow, due to its high viscosity and low vapor pressure. An inhomogeneous flow through the initial portion of the reactor exists and consequently, the sample taken though the capillary tube is not representative of the total flow. Although the material that is mixed with the water $/ \mathrm{O}_{2}$ phase may react quickly, not all of it is mixed and the TOC measurements appear artificially low. The other possible explanation is that the oil mixes promptly, but the intermediates formed in the first several seconds (such as methane, ethylene, ethane, etc.) are volatile and not soluble in water. The quenched sample yielded less organic carbon than it should because the sample, when cooled, was not a single homogeneous liquid solution and the hydrocarbon gases and high-vapor-pressure insoluble liquids are lost to the environment during collection.

\section{Sample composition}

The second possible explanation raises an important issue regarding all of the samples taken, not just those for the lubricating oil. Insoluble partially oxidized, reformed, or cracked lighter gaseous and liquid hydrocarbons (such as methane and lighter kerosene components), produced as intermediate reaction products will not necessarily appear in the effluent TOC quantitatively. This is best illustrated by the fact that standards of the JP-5 prepared even at several ppm did not produce consistent results in TOC analysis. If this were occurring, all of the samples taken, and not simply those from the early-time capillary tube sampling would be inaccurate. TOC analysis would not seem to be an appropriate way to characterize the reaction rate for feeds that are initially insoluble in water or produce insoluble or volatile intermediates. This concern is highlighted by noting that in Figure 5 the TOC curves for the low temperature points extrapolate to a TOC of about $50 \%$ of the feed.

\section{Sequential reaction model}

We can analyze in greater detail, at least for the JP-5 results for which we have sufficient data, the possibility that the liquid effluent mixture contains insoluble, unreacted liquid hydrocarbons that are undetected by the TOC method due to sample inhomogeneities. A sequential reaction model is proposed. The first step is the conversion of the hydrocarbons to water-soluble intermediates. At short residence times, fairly high TOC values are measured, as high as $1900 \mathrm{ppm}$ at lower 
temperatures, indicating that nearly $45 \%$ of the carbon has been converted to watersoluble intermediates (WSI), probably alcohols and aldehydes. At $424{ }^{\circ} \mathrm{C}$, for instance, this occurs in 0.85 seconds. The second step is the subsequent oxidation of these intermediates to $\mathrm{CO}$ and $\mathrm{CO}_{2}$.

This model can be expressed as two simultaneous first order equations describing the process.

$$
\begin{aligned}
\mathrm{JP}-5 & \begin{array}{l}
\mathrm{k}_{1} \\
\Rightarrow
\end{array} \quad \text { water soluble intermediates } \quad \stackrel{\mathrm{k}_{2}}{=} \quad \mathrm{CO}_{2}, \mathrm{CO} \\
& \mathrm{d}[\mathrm{JP}-5] / \mathrm{dt}=-\mathrm{k}_{1}[\mathrm{JP}-5] \\
& \mathrm{d}[\mathrm{WSI}] / \mathrm{dt}=-\mathrm{k}_{1}[\mathrm{JP}-5]-\mathrm{k}_{2}[\mathrm{WSI}]
\end{aligned}
$$

The solution to this sequential description is

$$
[J P-5]=[J P-5]_{0} \exp \left(-k_{1} t\right)
$$

and

where

$$
[W S I]=\exp \left(-k_{2} t\right)\left\{k_{1}[J P-5]_{o}\left(\exp \left(\left(k_{2}-k_{1}\right) t\right)\right) /\left(k_{2}-k_{1}\right)+C\right\}
$$

$$
\mathrm{C}=-\mathrm{k}_{1}[\mathrm{JP}-5]_{\mathrm{o}} /\left(\mathrm{k}_{2}-\mathrm{k}_{1}\right)
$$

The data can be used in a least-squares fitting routine to determine $k_{1}(T)$ and $k_{2}(T)$, using the observed TOC equated to WSI in Equation 8 as the fitted parameter. Unfortunately, the form of the data prevents a solution with a consistent set of rate constants reproducing both the late-time data and the early-time data. This is not surprising since it is unlikely that a single first-order rate constant can cover such a wide range of conversion as discussed earlier. However, we can use the three earlytime data points to determine the amount of JP-5 that is expected to remain as a function of time and temperature based on a fit of Equation 8 to the measurements. Figure 8 shows a plot of the results for $420^{\circ} \mathrm{C}, 500^{\circ} \mathrm{C}$, and $550{ }^{\circ} \mathrm{C}$.

Table 4 shows the fitted values for $k_{1}$ and $k_{2}$ for the different temperatures. This analysis suggests that there is a fairly temperature-independent rate that represents the conversion of the initial feed to the WSI. The second rate, the oxidation of the WSI to $\mathrm{CO}$ and $\mathrm{CO}_{2}$, is strongly, dependent on temperature. This is a plausible result when all the processes in the experiment are considered. The first rate is a combination of two processes: mixing and the formation of intermediates. The mixing is likely to be relatively independent of temperature since it is a function of fluid-dynamical processes that depend on density and viscosity. These properties are not strongly varying functions of temperature over this range. The conversion to intermediates is an activated chemical process and is likely to be exponentially dependent on temperature. It appears this first step is dominated by a mixing 

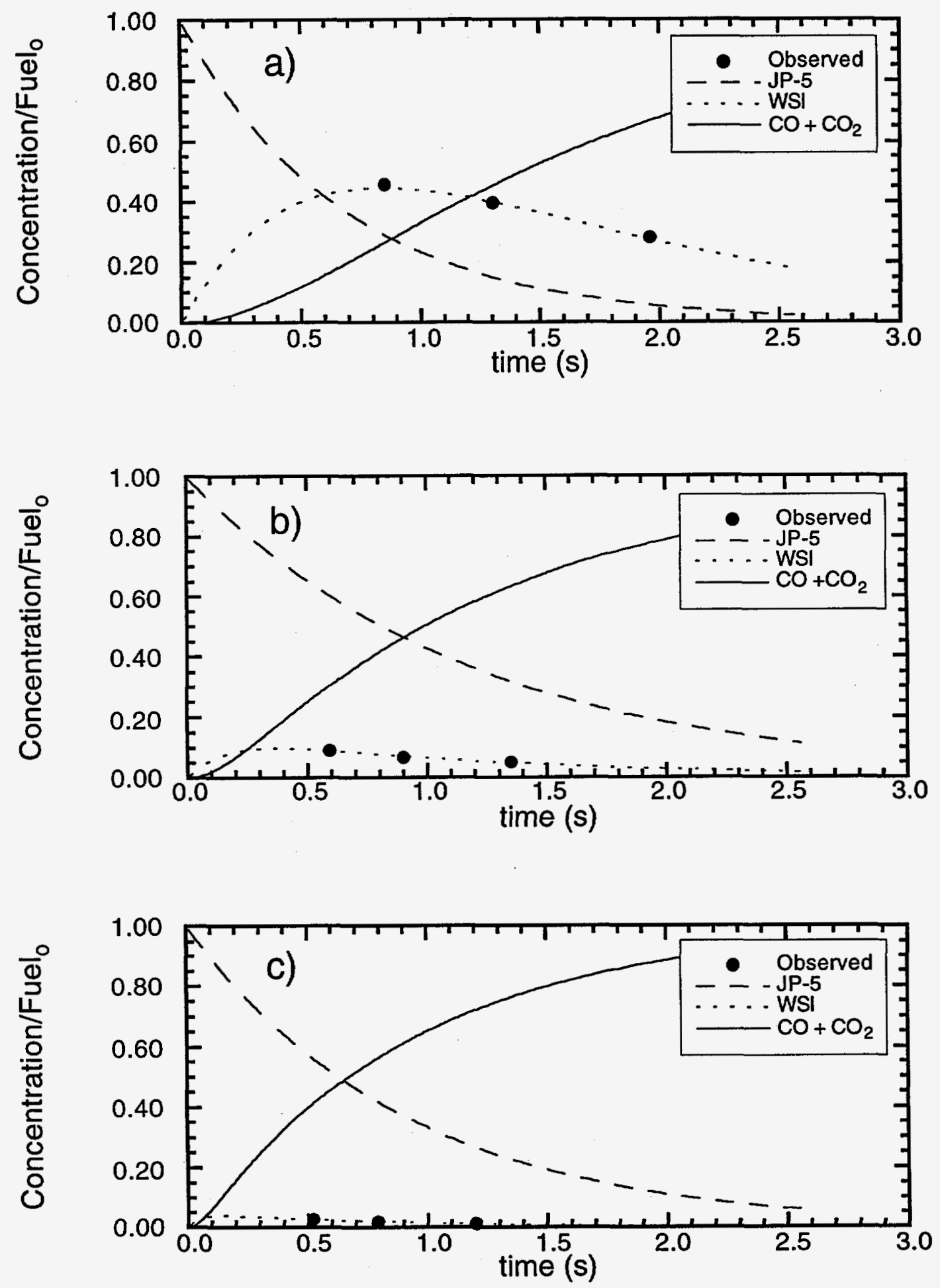

Figure 8. Results from the fit of Equation 8 to the observed TOC in the sample effluent for a) $420^{\circ} \mathrm{C}$, b) $500^{\circ} \mathrm{C}$, and c) $550^{\circ} \mathrm{C}$. 
process inasmuch as it does not exhibit a significant dependence on the temperature of the system. The second rate, characterized by $k_{2}$, is the oxidation of the WSI to CO and $\mathrm{CO}_{2}$ and varies with temperature exponentially. Figure 9 shows an Arrhenius plot of $k_{2}$ vs. $1 / \mathrm{T}$. The Arrhenius parameters are $E_{a}=25.6 \mathrm{kcal} / \mathrm{mole}$ and $A=$ $1.1 \times 10^{8} \mathrm{~s}^{-1}$ for the expression $\mathrm{k}_{2}=A \exp \left(-\mathrm{E}_{\mathrm{a}} / \mathrm{RT}\right)$.

Table 4 - Rate constants for sequential model of JP-5 oxidation

\begin{tabular}{ccc}
\hline $\begin{array}{c}\text { Temperature } \\
\left({ }^{\circ} \mathbf{C}\right)\end{array}$ & $\mathbf{k}_{\mathbf{1}}\left(\mathbf{s}^{-1}\right)$ & $\mathbf{k}_{\mathbf{2}}\left(\mathbf{s}^{-1}\right)$ \\
\hline 390 & 0.71 & 0.46 \\
\hline 420 & 1.46 & 0.96 \\
\hline 460 & 1.30 & 2.2 \\
\hline 500 & 0.85 & 6.3 \\
\hline 520 & 0.42 & 7.9 \\
\hline 550 & 1.10 & 23.8 \\
\hline
\end{tabular}

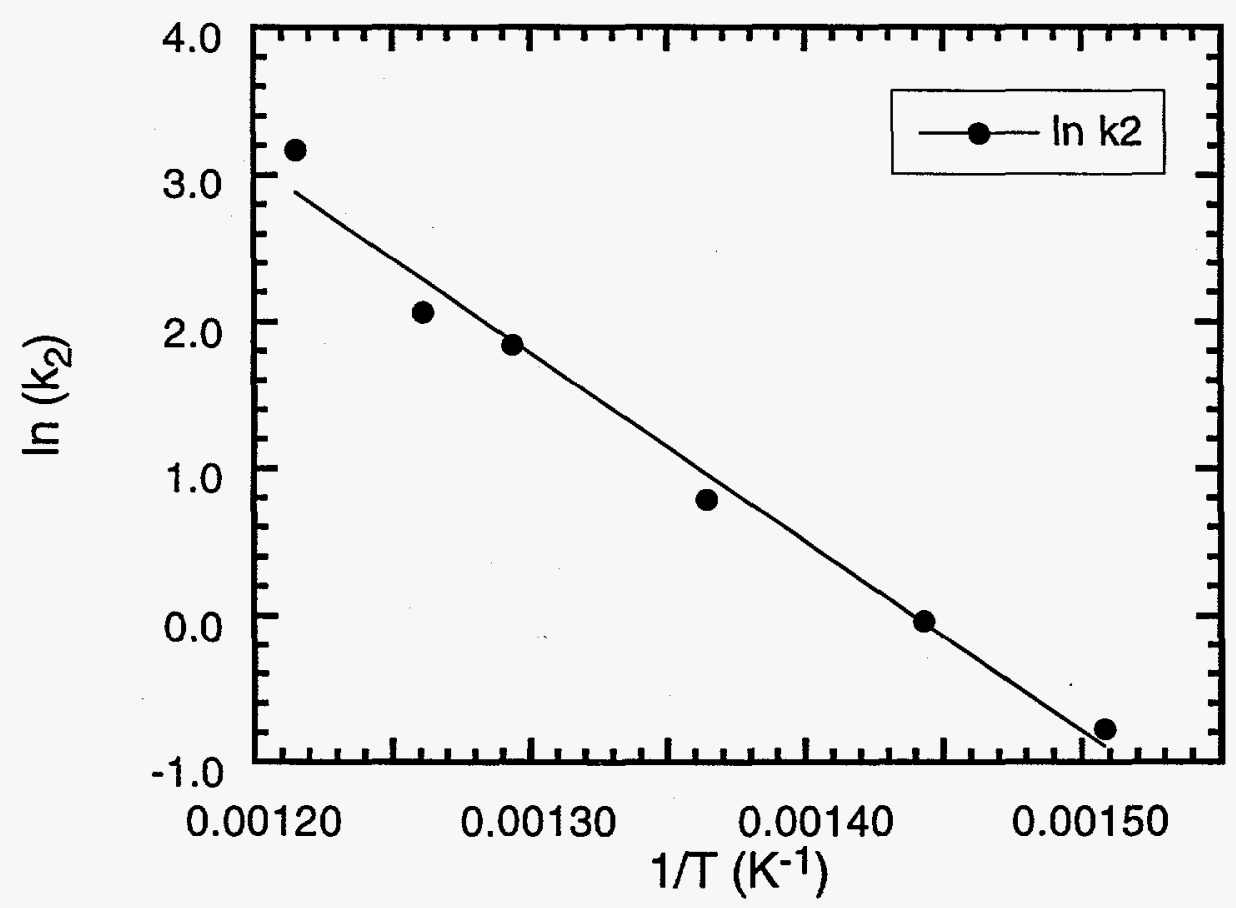

Figure 9. Plot of $\ln \left(\mathrm{k}_{2}\right)$ from Table 4 vs. 1/T showing the Arrhenius behavior of the fitted constant representing the conversion of the WSI to $\mathrm{CO}$ and $\mathrm{CO}_{2}$. 
We have attempted to use gas chromatography (GC) of the effluent from the JP-5 tests to aid in distinguishing between the first-order model and the sequential model. Although the GC detector response is not perfectly uniform for all organic compounds, to a first approximation the flame-ionization detector has a response proportional to the number of oxidizable carbons. As a result, the GC traces show a distribution species containing organic carbon.

Quantitative application of gas chromatography to only the liquid effluent is hampered by the same problem as TOC analysis. The volatile hydrocarbons will not be properly represented in the sample either due to loss during sampling or inadequate dissolution in water. As a result, the GC measurements show only that the composition of TOC in the samples is not JP-5, but is a more complicated mixture.

Figure 10 shows the GC traces for JP-5 in acetone and the trace for the $55 \mathrm{~S}(0.85 \mathrm{~s})$ sample at $424{ }^{\circ} \mathrm{C}$. The effluent sample is significantly different than the JP-5 feed. JP- 5 shows a large peak for the solvent (acetone) followed by a progression of many peaks representing $C_{n}$ hydrocarbons of increasing length. The effluent (in water) shows a broad off-scale feature at 3 minutes due to small organics in the $C_{1}-C_{4}$ range, although note that the large misshapen peak at about 4 minutes is due to water (solvent) disturbing the detector. At longer times the trace shows a poorly defined series of features in the range of the feed peaks followed by a broad smooth band at 28 minutes. This last band is probably partially oxidized alcohols, ketones and aldehydes of similar size to the hydrocarbon feed. The DB-5 GC column used for these measurements increases the retention time for these species relative to a comparably sized hydrocarbon. Obviously, the JP-5 in this sample has been converted to a large number of species, such that the GC resolves only the most prominent species. There are small species, compounds similar to the original feed, and large polar organics. Note that few of the features in the reacted sample align with peaks found in JP-5, other than two weak peaks at approximately 16 and 18 minutes.

\section{Summary of data set interpretation}

The results from the long-residence-time experiments are easily interpreted. Table 4 shows that, in the sequential model, with mixing time constants of approximately $1 \mathrm{~s}^{-1}$, essentially all of the organic carbon is converted in $5.5 \mathrm{~s}$ at $\mathrm{T}>565^{\circ} \mathrm{C}$. These data can be used reliably to calculate destruction efficiencies at reaction times greater than a few seconds.

The short residence-time results are plausibly interpreted by both the 1st order model and the sequential model. However, both models are an oversimplification 

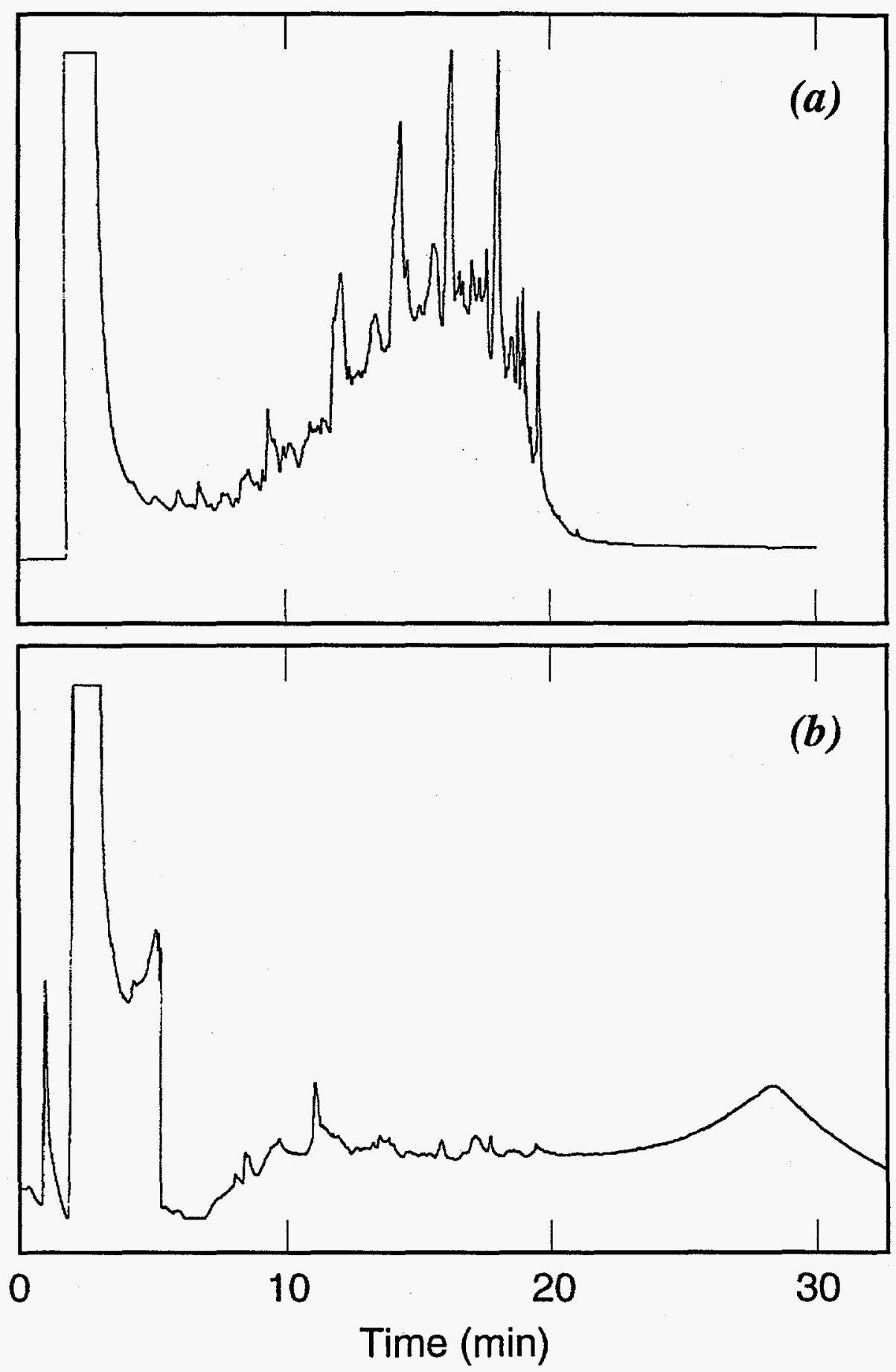

Figure 10. Gas chromatograms of a) JP-5 in acetone, and b) a sample of the reactor effluent taken at $0.85 \mathrm{~s}$ for the $420^{\circ} \mathrm{C}$ set. 
of the mixing/intermediate-conversion/mineralization process. Without collection of the gaseous effluent and a careful measurement of all the carbon in both effluent phases, the correct model to use to interpret the TOC measurements from the EHM processing is not clear. The first-order model suggests that there is very rapid mixing followed by oxidation (in less than 1 second) of a significant percentage of the fuel to $\mathrm{CO}$ and $\mathrm{CO}_{2}$. This percentage ranges from almost $60 \%$ at $390^{\circ} \mathrm{C}$ to $95 \%$ at $550{ }^{\circ} \mathrm{C}$. The consumption of the remainder of the organic carbon is a slower process. The sequential model suggests that, once mixed with the oxidizer and supercritical water, the oxidation of dissolved species is very rapid, with a rate constant as high as $23 \mathrm{~s}^{-1}$ at $550{ }^{\circ} \mathrm{C}$. The experimental configuration slows the conversion due to inadequate mixing on a timescale of less than one second. The sequential model suggests that the design of the injector is critical to the overall reaction rate at short residence times.

Consideration of apparent mixing times (see below) suggests that our experimental configuration does not significantly limit the mixing of the injected feed with the oxidizer for low-viscosity, low-boiling-point liquids. JP-5 and the hydraulic fluid can be considered to fall into this category. Although the sequential model reproduces the data, the lack of significant temperature dependence of $k_{1}$ tends to suggest that the simple first order model is more accurate. In the case of the high viscosity oil, however, the experimental evidence shows that the simple description of the shorttime reaction is incomplete. We suspect that only the longer-residence-time data, originating from samples of the entire effluent, is reliable in this case.

\section{Short Term Oxidation - Alcohols and JP-5}

\section{I-propanol and n-propanol oxidation}

The results for i-propanol that we recently reported ${ }^{8}$ are interesting in that a welldefined stable intermediate, acetone, is produced in significant quantities, delaying heat release. Because of the interest in using i-propanol or other alcohols as a supplemental fuel in the TWR, the rate of the complete oxidation process to $\mathrm{CO}_{2}$ has significant reactor design implications.

We undertook a series of experiments in the SFR to compare directly the oxidation of i-propanol and n-propanol. Using Raman spectroscopy as the analytical tool, we were able to follow the loss of fuel, production of intermediates including $\mathrm{CO}$ and acetone, and the production of $\mathrm{CO}_{2}$ during the oxidation of i-propanol and npropanol under SCWO conditions.

Figure 11a shows the conversion of i-propanol as a function of temperature and time, and Figure 11b shows the corresponding data for n-propanol. Note that the mixing time for i-propanol at $470{ }^{\circ} \mathrm{C}$ cannot be much greater than $0.3 \mathrm{~s}$, by examining the extrapolation back to zero conversion. The data show an apparent induction time at the lower temperatures where the initial reaction rate is slower than at later time. This is significantly different than the behavior of JP-5. The 
figures also show that the loss of n-propanol is slightly faster at a given temperature than the loss of $i$-propanol, such that comparable reactivity for n-propanol occurs about $20^{\circ} \mathrm{C}$ lower than for i-propanol. This is only part of the picture, however.

In the case of n-propanol, much more of the initial reactant is converted to $\mathrm{CO}$ and $\mathrm{CO}_{2}$ early in the reaction than is the case for i-propanol. Figures 12a and $12 \mathrm{~b}$ show the fraction of carbon in the system that exists as $\mathrm{CO}$ as a function of time and temperature during the oxidation of i-propanol and n-propanol and Figure 13a and $13 \mathrm{~b}$ show corresponding fractions of $\mathrm{CO}_{2}$. For example, in the case of $n$-propanol at $430{ }^{\circ} \mathrm{C}$ and 1.0 seconds, $20 \%$ of the carbon exists as $\mathrm{CO}_{2}, 40 \%$ exists as $\mathrm{CO}$, and the remaining $40 \%$ as n-propanol. At 2 seconds these values are $35 \%, 55 \%$, and $10 \%$ respectively. For i-propanol these values are $0 \% \mathrm{CO}_{2}$ and $\mathrm{CO}$ and $80 \%$ i-propanol at 1 second and $10 \% \mathrm{CO}_{2}, 15 \% \mathrm{CO}$, and $30 \%$ i-propanol, at 2 seconds. Much of the carbon during the oxidation of i-propanol exists as some other species, whereas in the case of n-propanol the route to $\mathrm{CO}$ and $\mathrm{CO}_{2}$ is more direct and faster, with no apparent carbon-containing intermediate being accumulated.

The data show that, in the case of i-propanol, the formation of a stable ketone, acetone, will significantly slow the rate of conversion of carbon to $\mathrm{CO}$ and $\mathrm{CO}_{2}$. Figure 14 shows that the fraction of carbon in the form of acetone in the oxidation of i-propanol at $430{ }^{\circ} \mathrm{C}$ is $20 \%$ at $1 \mathrm{~s}$ and $40 \%$ at 2 seconds. The same trend is true over the entire temperature range that has been examined.

Comparison with JP-5

Figure 15 compares the effective rate constant for the conversion of JP-5, i-propanol, n-propanol, and methanol ${ }^{5}$ evaluated by using Eq. 2, where $C / C_{0}$ is defined as the fraction of carbon that has not been converted to $\mathrm{CO}$ or $\mathrm{CO}_{2}$. For JP-5 this is simply the TOC $/ \mathrm{TOC}_{\mathrm{o}}$ (using the first order model). For the two propanols, this is a direct evaluation of the $\mathrm{CO}$ and $\mathrm{CO}_{2}$ concentration subtracted from the initial feed concentration. In the case of methanol, this is evaluated by summing the methanol and formaldehyde measured in Ref. 5 . In the case of the alcohols, the rate was evaluated at $1.0 \mathrm{~s}$ and for JP-5 it was evaluated approximately over the range of $0.52-$ $1.26 \mathrm{~s}$.

The $k_{\text {eff }}$ can be interpreted as the reciprocal of the time required to react $63.2 \%$ (1.0$1 /$ e) of the fuel to $\mathrm{CO}$ and $\mathrm{CO}_{2}$. Thus, approximately $50 \%$ of the heat content of the fuel will be released in a time $\approx \mathrm{keff}^{-1}$. At these temperatures, n-propanol is the most reactive of the three alcohols, but their rates have about the same steep dependence on temperature, becoming more reactive than JP-5 above $500^{\circ} \mathrm{C}$. The slope of the JP- 5 is significantly different; it is more reactive at the lower temperature, although the rate is still too slow for the initiation application. 

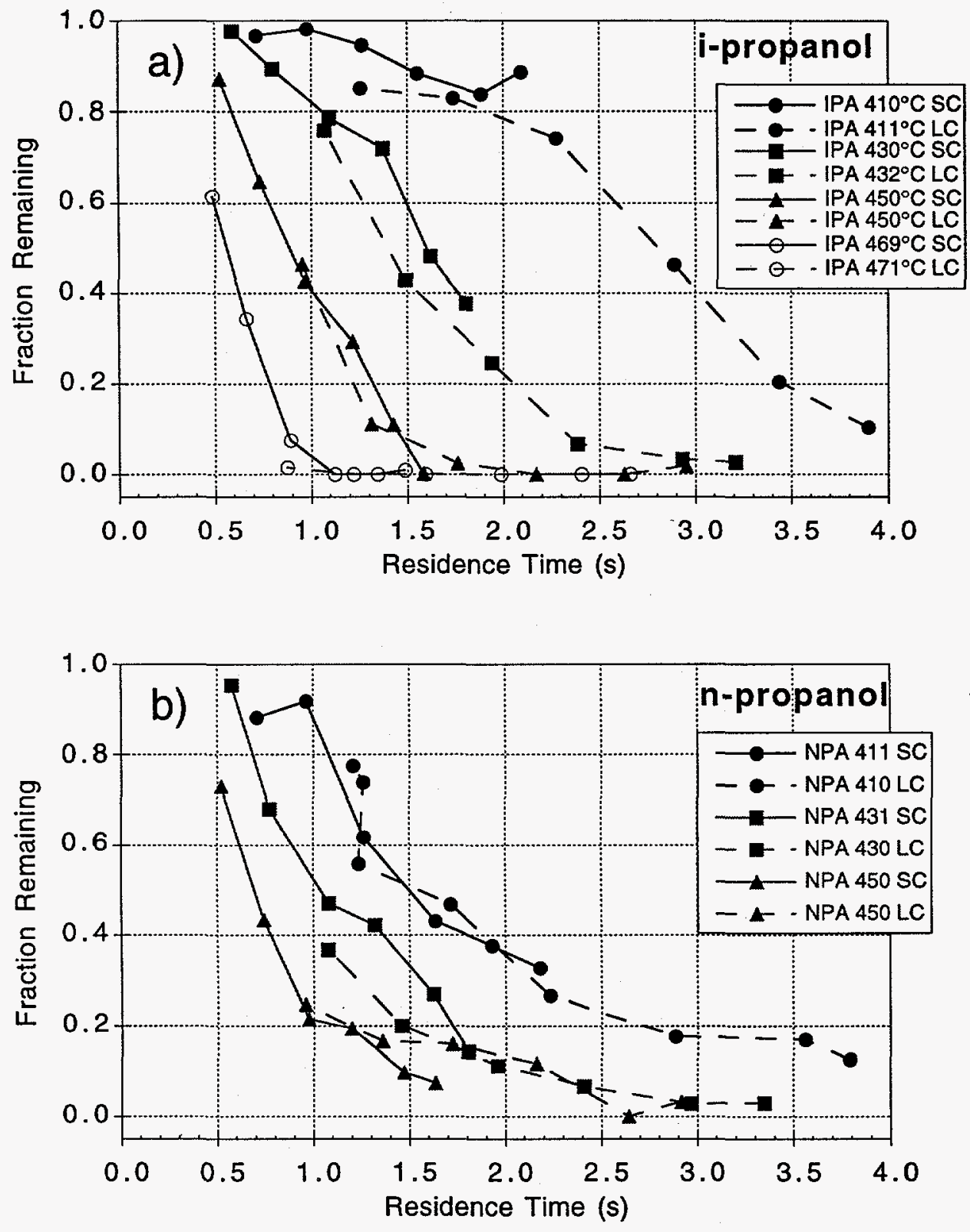

Figure 11. a) Oxidation of i-propanol by oxygen in supercritical water at four different temperatures at $25.0 \mathrm{MPa}$. The label on the ordinate, Fraction Remaining, refers to the fraction of feed i-propanol remaining at each measurement point (time) as detected by Raman spectroscopy. The "long and "short" positions of the cell in the flow reactor are $44.5 \mathrm{~cm}$ (SC) and $81.3 \mathrm{~cm}$ (LC). The different residence times for fixed cell positions are obtained by varying the total flow rate. b) Oxidation of npropanol by oxygen in supercritical water at three different temperatures at $25.0 \mathrm{MPa}$. The experimental methods were the same as used for i-propanol described above. 

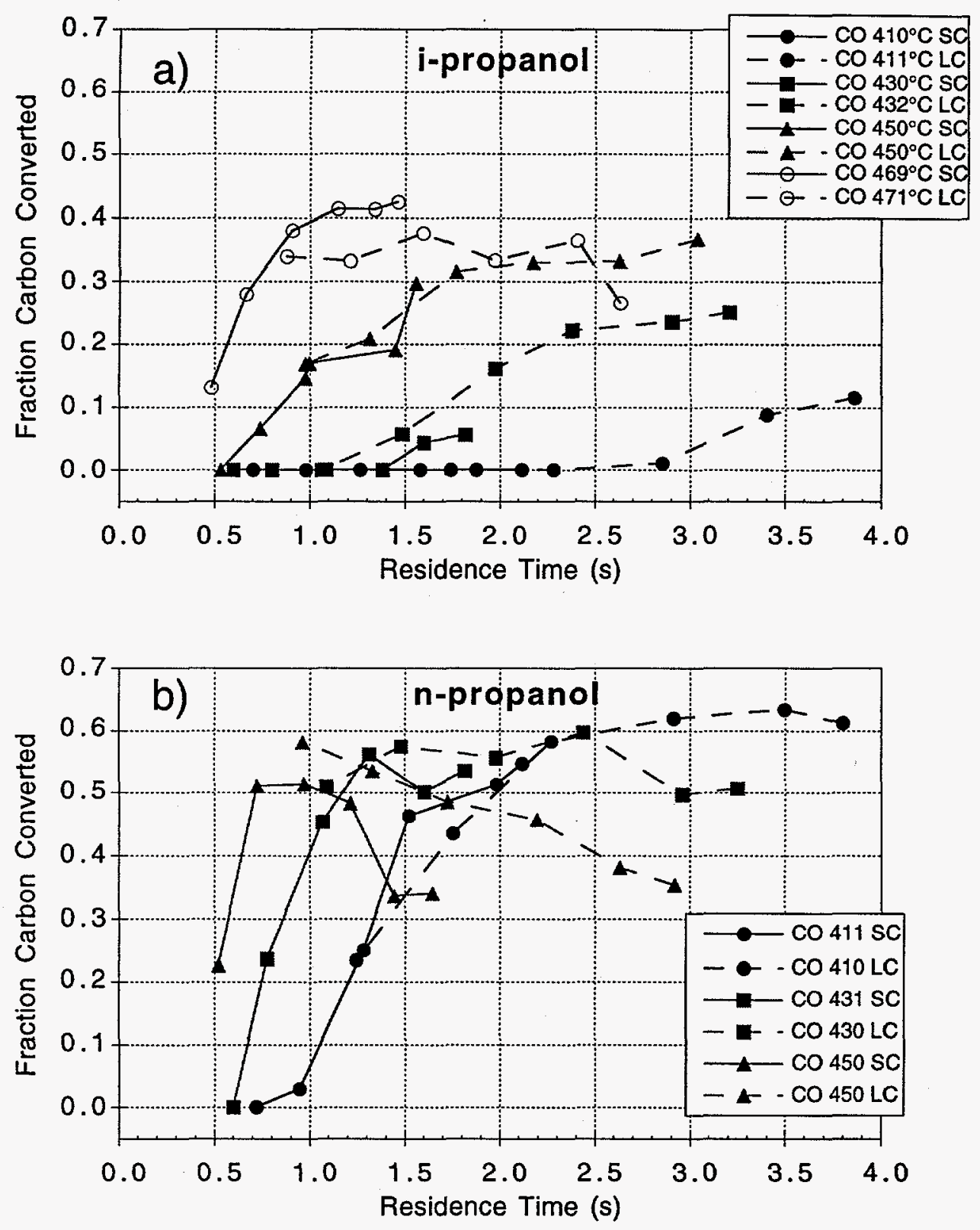

Figure 12. a) Production of $\mathrm{CO}$ during the oxidation of i-propanol in supercritical water at four different temperatures by oxygen at $25.0 \mathrm{MPa}$. Fraction Carbon Converted refers to the molar fraction of initial feed alcohol that exists as $\mathrm{CO}$. b) Production of $\mathrm{CO}$ during the oxidation of $\mathrm{n}$ propanol in supercritical water at three different temperatures by oxygen at $25.0 \mathrm{MPa}$. The experimental methods were the same as for $\mathrm{i}$ propanol described above. 

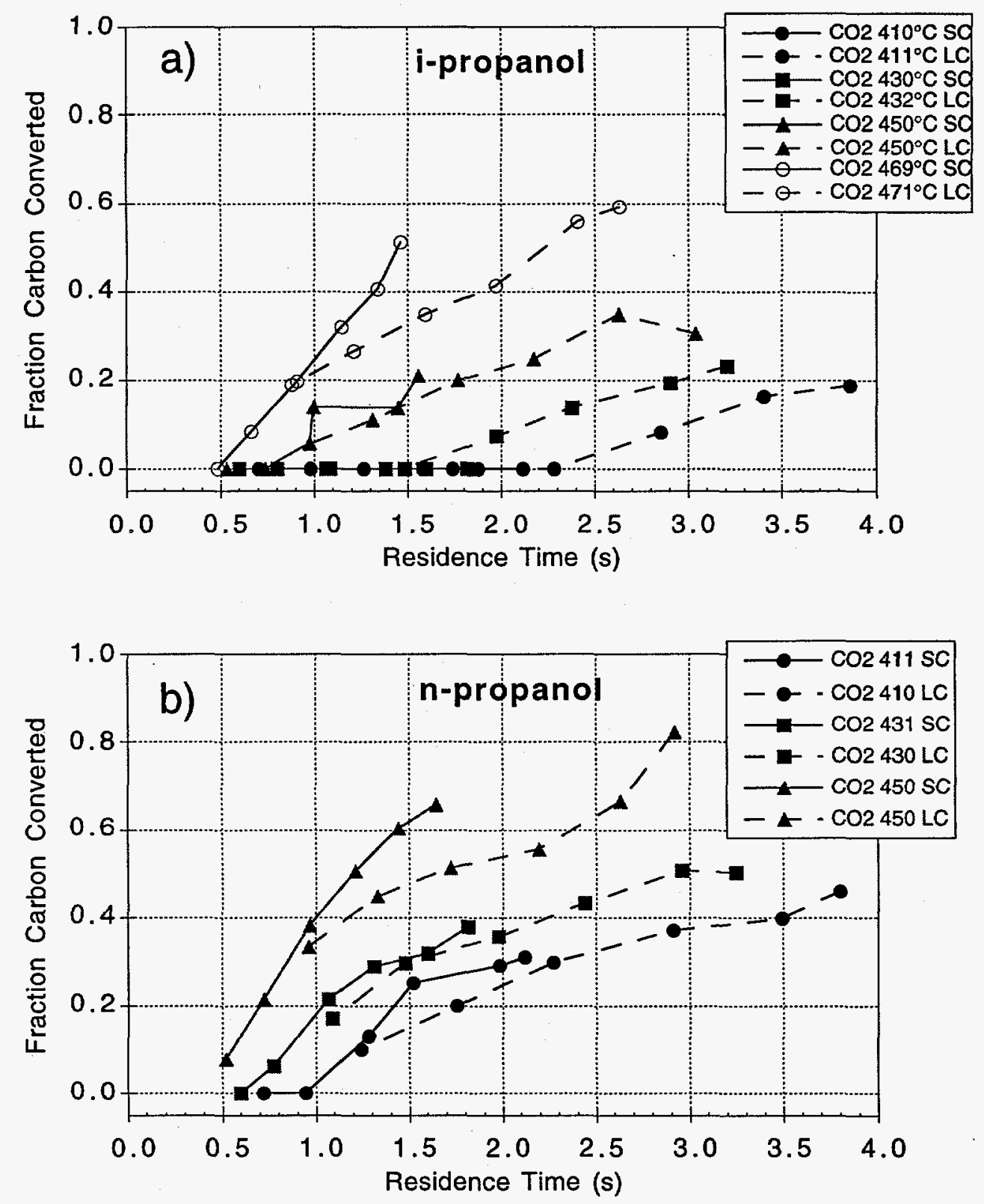

Figure 13. a) Production of $\mathrm{CO}_{2}$ during the oxidation of i-propanol in supercritical water at four different temperatures by oxygen at $25.0 \mathrm{MPa}$. Fraction Carbon Converted refers to the molar fraction of initial feed alcohol that exists as $\mathrm{CO}_{2}$. b) Production of $\mathrm{CO}_{2}$ during the oxidation of $\mathrm{n}$ propanol in supercritical water at three different temperatures by oxygen at $25.0 \mathrm{MPa}$. The experimental methods were the same as for ipropanol described above. 


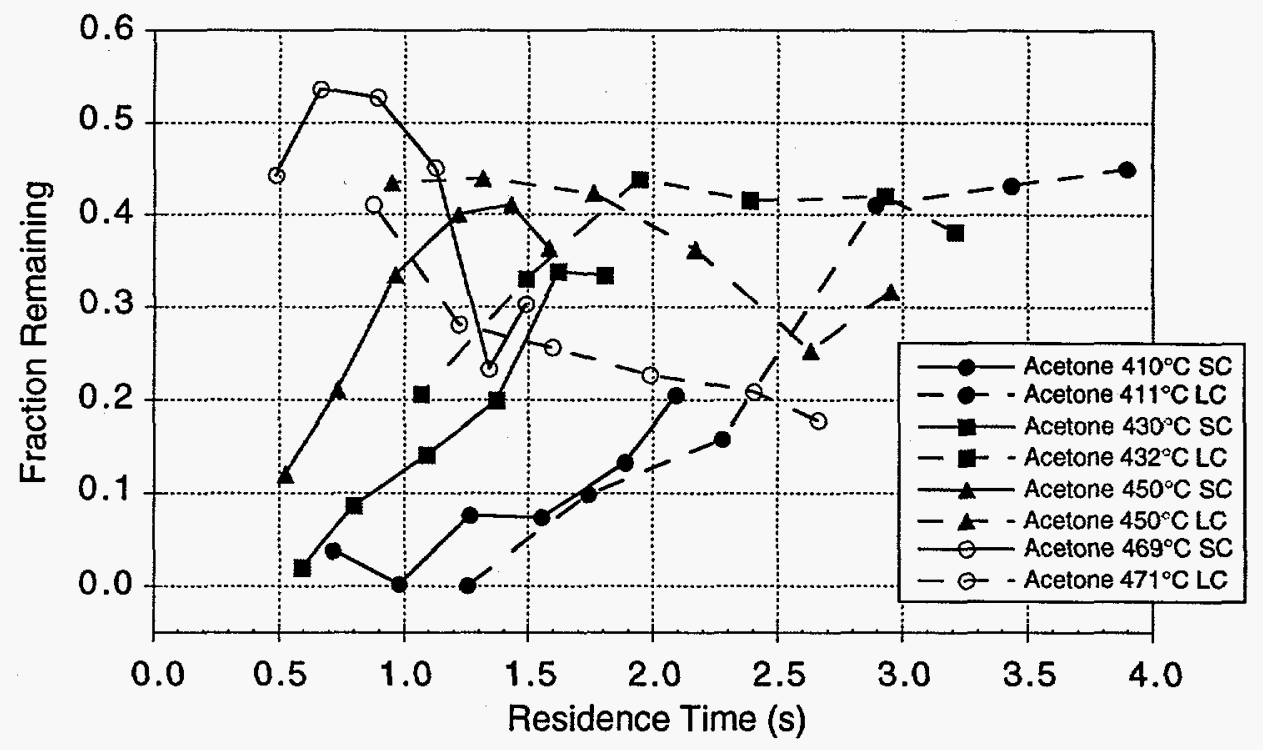

Figure 14. Production of acetone during the oxidation of i-propanol in supercritical water at four different temperatures by oxygen at $25.0 \mathrm{MPa}$. Fraction remaining refers to the molar fraction of initial feed ipropanol that exists as acetone. These data were recorded concurrently with the results in Figure 11a, 12a, and 13a.

The results for the oxidation of i-propanol show that, although it reacts rapidly relative to many organic species, it will not serve as a rapid source of heat in a waste feed system until the feed is already well above the critical temperature. I-propanol reaction is not sufficiently rapid to heat a subcritical feed to well above the critical temperature in a vessel in a real non-adiabatic reactor. It appears that $\mathrm{n}$-propanol will work very well at $470{ }^{\circ} \mathrm{C}$, releasing much of its heat of combustion in approximately 100 milliseconds. Expressed another way, according to Figure 15, approximately $1 / \mathrm{e}$ of the initial feed (representing a significant heat release) will be left after $0.5 \mathrm{~s}$ at $445^{\circ} \mathrm{C}$. The benchmark time of $0.5 \mathrm{~s}$ is used as a reasonable mixing time. Any reaction faster than this will become mixing limited and the kinetics will become less important. Some caution should be taken here since these rates were evaluated at $1.0 \mathrm{~s}$. The raw data show that only about $25 \%$ of the n-propanol is mineralized in $0.5 \mathrm{~s}$ at $450{ }^{\circ} \mathrm{C}$ (see Figures 12 and 13). This is because of a short induction time in the first few hundred milliseconds of the reaction, rendering inaccurate extrapolation of the $1.0 \mathrm{~s}$ data to very short times. 


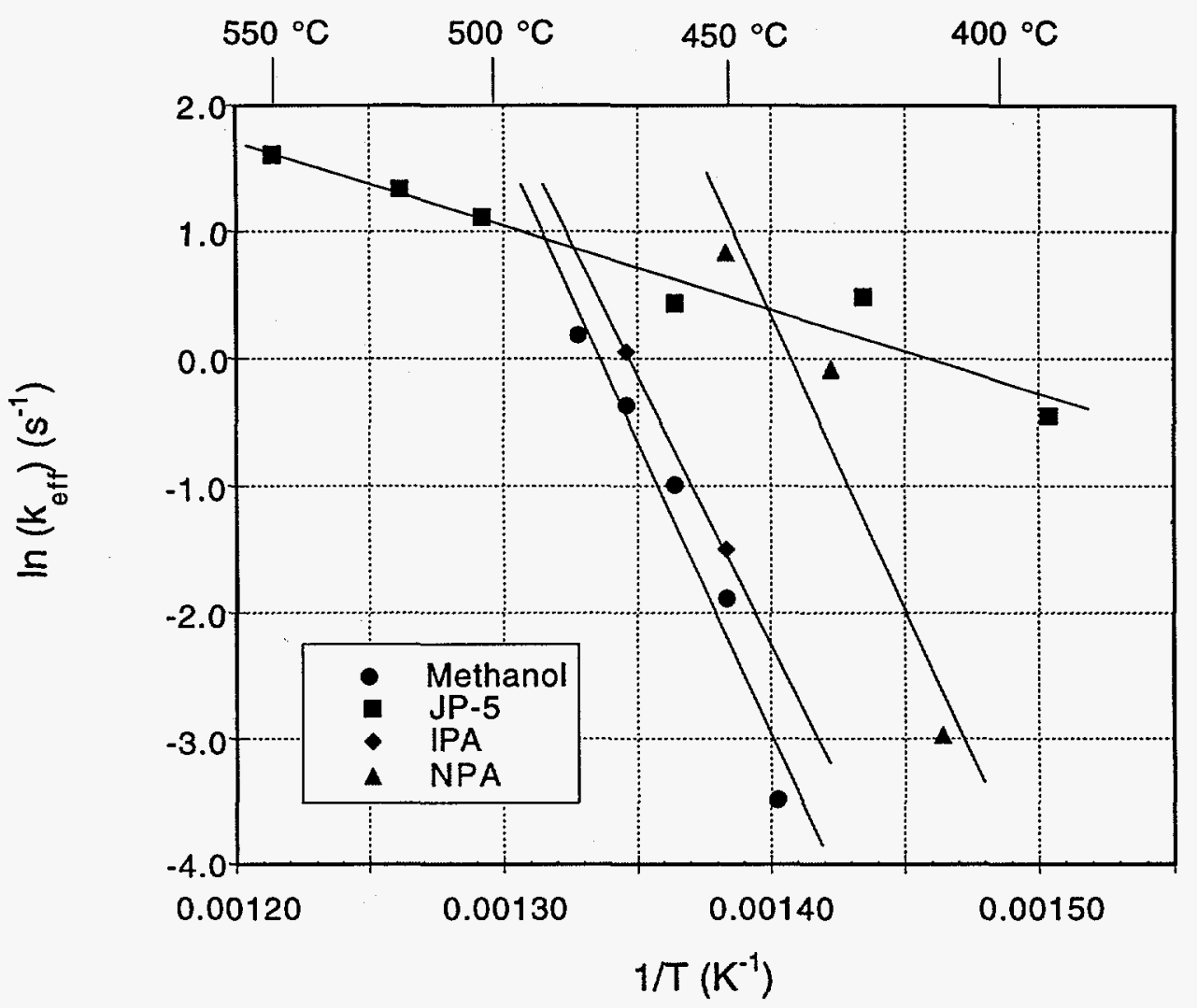

Figure 15. Arrhenius plot of the effective reaction rate constants ( $\left.k_{\text {eff }}\right)$ for methanol, JP-5, i-propanol, and n-propanol.

\section{Hydrogen Peroxide as an Oxidizer}

\section{SCVR Experiments}

Our cell reactor is an optically accessible, constant volume, externally heated highpressure vessel designed to be used for measuring reaction rates that occur on the $>20 \mathrm{~s}$ time scale. The experiments reported here covered the temperature range from $340{ }^{\circ} \mathrm{C}$ to $400{ }^{\circ} \mathrm{C}$ at a nominal pressure of $27.5 \mathrm{MPa}$ (4000 psi). Depending on the initial starting pressure, there was an approximately $300-800$ psi pressure increase in the reactor due to the injection of the oxidizer (and subsequent conversion of hydrogen peroxide to molecular oxygen and water). The magnitude of this increase was difficult to predict and as a result the seven runs reported here varied in final pressure from $23.5-27.5 \mathrm{MPa}$ (3500 psi to $4200 \mathrm{psi}$ ).

We used Raman spectroscopy to monitor directly the concentration of i-propanol as a function of time. Raman spectra (which are proportional to i-propanol 
concentration), temperature, and pressure were continuously recorded. The individual Raman spectra were then analyzed to produce a measurement of remaining i-propanol vs. time.

A typical experiment followed these procedural steps: 1) a solution of $2 \mathrm{wt} \% \mathrm{i}$ propanol was injected into the preheated reactor and allowed to equilibrate at the preset reaction temperature while the Raman signal was monitored to determine that no pyrolysis occurred; 2) a $30 \mathrm{wt} \% \mathrm{H}_{2} \mathrm{O}_{2}$ ambient temperature solution was injected into the reactor over a period of approximately 15 seconds; 3 ) Raman spectra of i-propanol were recorded every 10 seconds.

Table 5 presents the variation of the effective rate constant, $k_{\text {eff }}$, of the reaction with temperature, where we define $k_{\text {eff }}$ as the reciprocal of the time at which the concentration of $\mathrm{i}$-propanol has dropped to $1 / \mathrm{e}$ of its original concentration. Also included in the table are the results from the flow-reactor experiments for $\mathrm{i}$ propanol from Figure 12, and a point taken at $400{ }^{\circ} \mathrm{C}$ not reported in Figure 12 (experimental conditions were slightly different for this measurement). The $k_{\text {eff }}$ was determined from the flow reactor experiments by using the same definition. Note that the $\mathrm{k}_{\mathrm{eff}}$ for the higher temperature points are on the order of the oxidizer addition rate, and likely represent a convolution of the reaction rate and the addition rate. The temperature rise in the fluid detected for each run is also listed below. Note that the reactor is not adiabatic - the overly small temperature increases indicate that the rate of heat transfer to the walls is high compared to the energy release rate.

Table 5 - Results from Cell Reactor and Flow Reactor for I-propanol Oxidation

\begin{tabular}{cccc}
\hline Run \# & $\begin{array}{c}\text { T Initial } \\
\left({ }^{\circ} \mathbf{C}\right)\end{array}$ & $\begin{array}{c}\text { TRise } \\
\left({ }^{\circ} \mathbf{C}\right)\end{array}$ & $\begin{array}{c}\mathbf{k}_{\text {eff }} \\
\left(\mathbf{s}^{-1}\right)\end{array}$ \\
\hline 1 & 346 & 5 & 0.0071 \\
\hline 2 & 343 & 7 & 0.0076 \\
\hline 3 & 372 & 12 & 0.010 \\
\hline 4 & 370 & 12 & 0.0090 \\
\hline 5 & 395 & 4 & 0.040 \\
\hline 6 & 392 & 10 & 0.066 \\
\hline 7 & 402 & 12 & 0.100 \\
\hline & & & \\
\hline F.R.1 & 400 & - & 0.13 \\
\hline F.R.2 & 410 & - & 0.31 \\
\hline F.R.3 & 430 & - & 0.59 \\
\hline F.R.4 & 450 & - & 0.83 \\
\hline F.R.5 & 470 & - & 1.4 \\
\hline
\end{tabular}




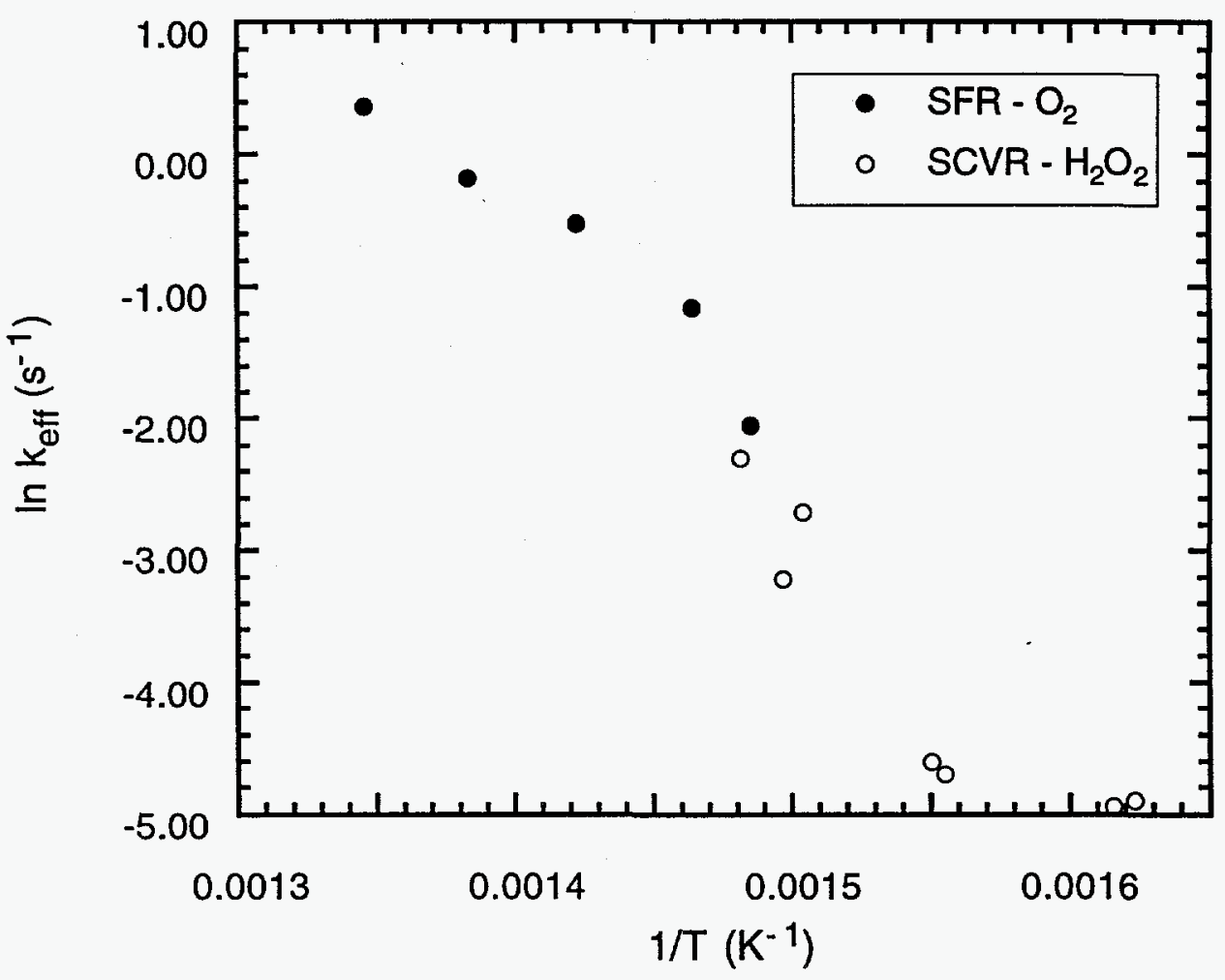

Figure 16. Arrhenius plot of the effective reaction rate constants $\left(k_{\text {eff }}\right)$ of ipropanol with hydrogen peroxide in the SCVR and with oxygen in the SFR.

Comparison to flow reactor experiments:

The results from these two different reactors are presented in Figure 16 . The higher temperature points from the flow reactor, using oxygen as the oxidizer, merge fairly smoothly to the lower temperature results from the constant-volume reactor using injected hydrogen peroxide. It appears that there is no advantage to using $\mathrm{H}_{2} \mathrm{O}_{2}$ as an injected oxidizer. This is because the thermal decomposition of hydrogen peroxide proceeds to $\mathrm{O}_{2}$ much faster than the oxidation.

We reiterate, however, that the $\mathrm{H}_{2} \mathrm{O}_{2}$ addition rate in the $402{ }^{\circ} \mathrm{C}$ experiment is comparable to the oxidation rate such that the observed $\tau_{\text {eff }}$ of $10 \mathrm{~s}$ is only a very rough estimate. The values at $395^{\circ} \mathrm{C}$ are more reliable. 


\section{Summary and Future Research Needs}

Design issue recommendations

A series of experiments in the supercritical fluids reactor have generated data for the development of a transpiration wall supercritical water oxidation reactor designed to dispose of excess hazardous material present on naval vessels. The specific design parameters for the system require an accurate knowledge of destruction efficiency vs. time and temperature. Three candidate materials known to be present in large quantity on ships were selected for testing. The results show that these materials can be fully destroyed $(99.9 \%)$ in approximately 5 seconds at temperatures near $600^{\circ} \mathrm{C}$. The results vary smoothly and predictably with temperature such that extrapolation to higher temperatures beyond the experimental capabilities of the SFR can be made with reasonable confidence.

These measurements and analyses are designed to develop a basis for specific recommendations regarding the design of transpiration wall supercritical water oxidation reactors. Although there are some concerns remaining with regard to the use of aqueous phase TOC analytical measurements alone to determine for the evaluation of destruction efficiencies, we believe the magnitude of the errors that are introduced will not significantly change the recommendations that are listed below. However, a great deal more fundamental work remains to be done to fully characterize pathways and rates of the overall oxidation process of hydrocarbon mixtures in supercritical water.

The answers to the specific design questions that were posed in the Introduction are given below.

\section{Question 1:}

What is the time/temperature relationship for the destruction of the three representative EHMs to a conversion of $99.9 \%$ and how well can this relationship be extrapolated to temperatures that are not within the operational range of the supercritical fluids reactor?

\section{Answer:}

The data show that the conversion rate of all three EHMs that were examined is a strong function of temperature and that the temperature dependence is smooth and predictable. Regardless of the concerns that we have about the short-residence-time results, the high conversion data suggest that $99.9 \%$ DRE can be achieved for all three species in about 5 seconds at temperatures above $600^{\circ} \mathrm{C}$. The $\mathrm{k}_{\text {eff }} \mathrm{s}$ appear to - vary smoothly with temperature in an Arrhenius fashion, permitting confident extrapolation to higher temperatures. As is indicated in the MSDSs for the JP-5 and hydraulic fluid, these materials contain oxidation inhibitors. Presumably, the lubricating oil formulation also is designed to inhibit oxidation. Inasmuch as these materials appear to oxidize at rates comparable to simple alcohols, it does not appear 
that additives designed to inhibit lower temperature oxidation participate in the oxidation under SCWO conditions.

\section{Question 2:}

What is the time/temperature relationship that produces substantial conversion of the JP-5 and several candidate alcohols to be used as injector reaction initiation fuels?

\section{Answer:}

Because of the concerns over the interpretation of the short-residence-time data for JP-5, the conclusion here is not as certain as for Question 1. However, based on the data shown in Figure 15, it appears that JP-5 is an excellent candidate as a reactioninitiation fuel. It would be interesting to compare the effective fuel consumption rate for JP-5 to refined kerosene without any oxidation-inhibiting additive. It appears however, that if initiation is desired with a delay time of $\leq 0.5 \mathrm{~s}$ that the best initiation fuel is n-propanol. Its heat of combustion is not significantly smaller than that of JP-5, and a small amount of heat release will greatly accelerate the reaction. The detailed experiments that have been conducted on n-propanol lend very high confidence in this conclusion. In addition, n-propanol can be delivered easily over a range of concentrations since it is soluble in water at all concentrations and temperatures.

If expense and availability are key factors, it appears that nearly the same results can be obtained using a hydrocarbon fuel. However, there may be operational concerns regarding the mixing of the fuel and stability during preheating that leave some outstanding operational issues to be resolved before this strategy can be used in a design with confidence.

\section{Question 3:}

What is the effect of the addition of hydrogen peroxide in the oxidizer feed system, and could a method based on $\mathrm{H}_{2} \mathrm{O}_{2}$ in the oxidizer feed be used to lower the required injector initiation temperature?

\section{Answer:}

The results on i-propanol clearly show that there is no great advantage in injecting concentrated $\mathrm{H}_{2} \mathrm{O}_{2}$ solutions as a reactive oxidizer to enhance the initiation rate in an injector for feeds below the critical temperature. The overall fuel consumption rate is similar to that which would be predicted for oxygen. This is because at temperatures less than $400{ }^{\circ} \mathrm{C}$, the thermal decomposition rate $\mathrm{H}_{2} \mathrm{O}_{2}$ to $\mathrm{OH}$ is on the order of $1.0 \mathrm{~s}^{-1}$. More importantly, however, the subsequent chain termination reactions resulting in the formation of molecular oxygen are faster than the reaction of $\mathrm{OH}$ with the fuel at such a low temperature. As a result, the $\mathrm{OH}$ radicals that are formed never react with a detectable amount of fuel and in less than a second, all of the $\mathrm{H}_{2} \mathrm{O}_{2}$ is converted to oxygen. 


\section{Future Research Needs}

The scope of the project did not permit for a careful examination of many of the details of the reaction chemistry. Several interesting observations were made that warrant additional investigation, the results from which would have a direct impact on the reliable operation of TWR reactors.

Other less expensive initiation fuels should be considered. Although ethanol has not been examined in this context, measurements similar to the propanol experiments would be very useful since ethanol is readily available, inexpensive, and soluble in water. It may have a reactivity much closer to that of $n$-propanol than to i-propanol or methanol.

It would also be useful to compare the behavior of several single-component light, liquid hydrocarbons to the behavior of the JP- 5 mixture to determine if there is an effect on the oxidation of the complicated fuel mixture due to the presence of more reactive alkanes that function as initiator species.

Analysis of the gaseous effluent for light hydrocarbons and $\mathrm{CO}$ is especially important. Not only would this give confidence in the overall rate expressions by providing closure in the carbon balance in the system, it would also quantify the amount of $\mathrm{CO}$ emitted. This is important for both operator safety and permitting.

One particular observation during the course of these tests needs further investigation. There is considerable evidence from the early-time kinetics that the high viscosity oil may not exhibit the same rapid mixing characteristics of the lighter hydrocarbon feeds. Some of this material could char and eventually plug injector tubing. The slow mixing of some of the EHMs may place an important limitation on the maximum destruction efficiency of the short-residence time system $(<5.0 \mathrm{~s})$; there is an apparent induction time, simply due to mixing, that cannot be shortened by increasing the temperature. In fact, we suspect that this time is increases at higher temperature due to the decrease in density of the supercritical water and subsequent weakening of the turbulent shearing forces that cause mixing on a macroscopic scale. It appears that residence times of 5 seconds (in our configuration) afford adequate mixing such that high conversions are observed. However, such an effect could significantly impact the thermal release rate in different sections of the reactor.

\section{- Acknowledgements}

This work was supported at Sandia in part by DARPA from proposal \# 084950316 and in part by the Strategic Environmental Research and Development Program (SERDP) project \# $364-\mathrm{DOE}$. 


\section{References}

1 K. S. Ahluwalia, M. F. Young, B. L. Haroldsen, B. E. Mills, M. C. Stoddard, and C. D. Robinson, in First International Workshop on Supercritical Water Oxidation (Department of Energy, Jacksonville, Florida, 1995), pp. Session VI: Innovative Reactor Design to Mitigate Corrosion Effects.

2 H. H. Mueggenburg, J. W. Hidahl, E. L. Kessler, and D. C. Rouser, in AIAA/SAE/ASME/ASEE 28th Joint Propulsion Conference and Exhibit (American Institute of Aeronuatics and Astronautics, Nashville, TN, 1992).

3 H. E. Barner, C. Y. Huang, T. Johnson, M. A. Martch, and W. R. Killilea, Journal of Hazardous Materials 31, 1-17 (1992).

4 R. G. Hanush, S. F. Rice, T. B. Hunter, and J. D. Aiken, Sandia Report SAND968203 Sandia National Laboratories, Livermore, CA, 1995.

5 S. F. Rice, T. B. Hunter, Å. C. Rydén, and R. G. Hanush, Industrial and Engineering Chemistry Research 35, 2161-2171 (1996).

6 R. R. Steeper, Sandia Report SAND96-8208 (Sandia National Laboratories, Livermore, CA, 1995).

7 R. R. Steeper, S. F. Rice, M. S. Brown, and S. C. Johnston, Journal of Supercritical Fluids 5, 262-268 (1992).

8 T. B. Hunter, S. F. Rice, and R. G. Hanush, Industrial and Engineering Chemistry Research 35, 3984-3990 (1996). 
INITIAL DISTRIBUTION

Dr. Robert Marianelli

U.S. Dept. Of Energy

19901 Germantown Rd.

Germantown, MD 20874

Dr. Robert W. Holst

SERDP Program Office

Program Manager for Compliance and

Global Environmental Change

901 North Stuart Street, Suite 303

Arlington, VA 22203

Ed Ansell

US Army Defense Ammunition

Center

Attn: SMCAC-TD

Savanna, IL 61074-9639

Jenny Dowden

Labat-Anderson Incorporated

8000 Westpark Dr.

Suite 400

McLean, VA 22102

John Harrison

SERDP Program Office

901 North Stuart Street, Suite 303

Arlington, VA 22203

Jim Hurley

US AF AL/EQS

139 Barnes Drive, Suite 2

Tyndall Air Force Base, FL 32403

Richard Kirts

Naval Civil Engineering Laboratory

560 Laboratory Dr.

Port Hueneme, CA 93043-4328
Crane Robinson

Arament Research

Development \& Engineering Center

(ARDEC)

SMCAR-AES-P

Building 321

Picatinny Arsenal, NJ 07806-5000

Dr. Peter Schmidt

Office of Naval Research

Chemistry Division

800 North Quincy Street

Arlington, VA 22217-5660

Dr. Regina E. Dugan

DARPA/DSO

3701 N. Fairfax Dr.

Arlington VA

22203-1714

Dr. Robert Shaw

Chemical \& Biological Sciences Div.

U.S. Army Research Office

Research Triangle Park, NC 27709-2211

Prof. Martin A. Abraham

The University of Tulsa

Department of Chemical Engineering

600 South College Avenue

Tulsa, OK 74104-3189

Prof. Joan F. Brennecke

University of Notre Dame

Department of Chemical Engineering

Notre Dame, IN 46556

Prof. Klaus Ebert

Kernforschungszentrum Karlsruhe

Institut fur Heisse Chemie

Postfach 3640

D-76021 Karlsruhe

Germany 
Dr. Robert E. Huie

National Institute of Standards and

Technology

Chemistry A261

Gaithersburg MD 20899

Prof. Earnest F. Gloyna

University of Texas at Austin

Environmental and Health

Engineering

Austin, TX 78712

Prof. Keith Johnston

University of Texas at Austin

Chemical Engineering Dept.

26th and Speedway

Austin, TX 78712-1062

Prof. Micheal T. Klein

Chairman

University of Delaware

Chemical Engineering Dept.

Colburn Labs Academic Street

Newark, DE 19716-2110

Prof. Phillip E. Savage

University of Michigan

Chemical Engineering Department

Herbert H. Dow Building

Ann Arbor, MI 48109-2136

Prof. Jefferson W. Tester

Massachusetts Institute of Technology

Energy Laboratory

Room E40-455

77 Massachusetts Avenue

Cambridge, MA 02139

K.S. Ahluwalia

Foster Wheeler Development

Corporation

Engineering Science \& Technology

12 Peach Tree Hill Road

Livingston, NJ 07039
Armand A. Balasco

Arthur D. Little Inc.

Acorn Park

Cambridge, MA

02140-2390

Dr. Hiroshi Inomata

Tohoku University

Aoba Aramaki

Sendai 980

JAPAN

Thomas G. McGuinness

255 41st St.

Apt. 9

Oakland CA 94611

Carol A. Blaney

Kimberly-Clark

1400 Holcomb Bridge Rd.

Roswell, GA 30076-2199

Dr. David A. Hazelbeck

General Atomics

M/S 15-100D

3550 General Atomics Court

San Diego, CA 92121-1194

W. Killilea

General Atomics

3550 General Atomics Court

San Diego, CA 92121-1194

Richard C. Lyon

Eco Waste Technologies

2305 Donley Drive

Suite 108

Austin, TX 78758-4535

Dan Greisen

1940 Alabama Ave

PO Bxo 3530

Rancho Cordova, CA 95741-3530 
Dr. Steven J. Buelow

CST-6

Los Alamos National Lab.

Los Alamos, NM 87545

Philip C. Dell'Orco

Los Alamos National Laboratory

Explosives Technology \& Safety C920

Los Alamos, NM 87545

Dr. Albert Lee

NIST

Bldg. 221 Room B312

Gaithersburg, MD 20899

Prof. Jean Robert Richard

CNRS

Combustion Laboratory

1C Avenue de la Recherche Scient.

Orleans 45071

France

Dr. Gregory J. Rosasco

Nat'l Institute of Standards and

Technology

Division 836, Bldg. 221, Rm B-312

Gaithersburgh, MD 20899

MS0828 P. J. Hommert, 1503

MS0701 R. W. Lynch, 6100

MS0735 D. E. Arvizu, 6200

6203 A. P. Sylwester

6211 G. A. Carlson

6212 N. B. Jackson

MS0756 G. C. Allen, 6607

MS9001 T. O. Hunter, 8000

Attn: 8100 M. E. John

8200 L. A. West

8400 R. C. Wayne

3
MS9054 W. J. McLean, 8300

MS9042 C. Hartwig, 8345

MS9051 L. Rahn, 8351

MS9055 F. Tully, 8353

MS9052 D. R. Hardesty, 8361 (2)

MS9052 S. W. Allendorf, 8361

MS9052 M. D. Allendorf, 8361

MS9052 L. L. Baxter, 8361

MS9052 S. G. Buckley, 8361

MS9052 M. M. Lunden, 8361

MS9052 T. A. McDaniel, 8361

MS9052 D. K. Ottesen, 8361

MS9052 C. Shaddix, 8361

MS9052 J. Aiken, 8361

MS9052 E. Croiset, 8361

MS9052 R. Hanush, 8361

MS9052 S. Rice, 8361 (20)

MS9053 R. Carling, 8362

MS9053 R. Steeper, 8362

MS9053 R. Gallagher, 8366

MS9101 B. Peila, 8411

MS9105 T. T. Bramlette, 8422

MS9105 J. Lipkin, 8419 
MS9406 B. Haroldsen, 8412

MS9406 H. Hirano, 8412

MS9406 C. LaJeunesse, 8412

MS9406 M. C. Stoddard, 8412

MS9007 j. Swearengen, 8419

MS9404 B. Mills, 8713

MS9021 Technical Communications Department, 8535, for OSTI

MS9021 Technical Communications Department, 8535/Technical Library, MS0899, 13414

MS0899 Technical Library, 13414 (4)

MS9018 Central Technical Files, 8523-2

(3) 